\title{
Insights on Slab-driven Mantle Flow from Advances in Three-dimensional modelling
}

\author{
Margarete A. Jadamec \\ Department of Earth and Atmospheric Sciences, University of Houston, Houston, TX USA
}

\section{Abstract}

The wealth of seismic observations collected over the past 20 years has raised intriguing questions about the three-dimensional (3D) nature of the mantle flow field close to subduction zones and provided a valuable constraint for how the plate geometry may influence mantle flow proximal to the slab. In geodynamics, there has been a new direction of subduction zone modelling that has explored the 3D nature of slabdriven mantle flow, motivated in part by the observations from shear wave splitting, but also by the observed variations in slab geometries worldwide. Advances in highperformance computing are now allowing for an unprecedented level of detail to be incorporated into numerical models of subduction. This paper summarizes recent advances from 3D geodynamic models that reveal the complex nature of slab-driven mantle flow, including trench parallel flow, toroidal flow around slab edges, mantle upwelling at lateral slab edges, and small scale convection within the mantle wedge. This implies slab-driven mantle deformation zones occur in the asthenosphere proximal to the slab, wherein the mantle may commonly flow in a different direction and rate than the surface plates, implying laterally variable plate-mantle coupling. The 3D slab-driven mantle flow can explain, in part, the lateral transport of geochemical signatures in subduction zones. In addition, high-resolution geographically referenced models can inform the interpretation of slab structure, where seismic data 
are lacking. The incorporation of complex plate boundaries into high-resolution, 3D numerical models opens the door to a new avenue of research in model construction, data assimilation, and modelling workflows, and gives 3D immersive visualisation a new role in scientific discovery.

6 Keywords: subduction, mantle dynamics, lithospheric deformation, numerical 7 modelling, high performance computing

\section{Introduction}

Geologic observations (Casey and Dewey, 1984; Bird, 2003; Eberhart-Phillips et al., 2003), geochemical constraints (Hoernle et al., 2008; Gazel et al., 2009; Heyworth et al., 2011; Durance et al., 2012), and geophysical data (Russo and Silver, 1994; Gudmundsson and Sambridge, 1998; Fischer et al., 2000; Smith et al., 2001; Syracuse and Abers, 2006; Long and Silver, 2008; Müller et al., 2008) from subduction zones indicate that the two-dimensional paradigm for plate tectonic boundaries is no longer adequate to explain the observations. For example, inspection of global tectonic features reveals lateral changes in trench geometry (Bird, 2003), lateral and radial changes in slab morphology (Jarrard, 1986; Gudmundsson and Sambridge, 1998; Gutscher et al., 2000; Grand, 2002; Lallemand et al., 2005; Syracuse and Abers, 2006; Li et al., 2008; Hayes et al., 2012), and lateral gradients in seafloor age, in both modern and ancient times (Sdrolias and Müller, 2006; Müller et al., 2008) (Figure 1). Subduction zones can have (a) a high radius of curvature, such as in the Lesser Antilles and Scotia subduction zones, (b) vary significantly in slab dip along strike, such as in Japan, Alaska, and South America, (c) have tears or slab gaps, as in the Middle America-South America subduction zones, and (d) have complex interactions at triple junctions (Figure 1) (Jarrard, 1986; Gudmundsson and Sambridge, 1998; Ratchkovski and Hansen, 2002; Lallemand et al., 2005; Syracuse and Abers, 2006; 
Nakajima and Hasegawa, 2007; Li et al., 2008; Hayes et al., 2012; Zhao et al., 2012;

Dougherty and Clayton, 2014; Scire et al., 2016; Syracuse et al., 2016).

The wealth of seismic observations collected over the past 20 years has raised intriguing questions about the three-dimensional nature of the mantle flow field close to subduction zones (Russo and Silver, 1994; Hall et al., 2000; Peyton et al., 2001; Smith et al., 2001; Hoernle et al., 2008; Zandt and Humphreys, 2008; Long and Silver, 2008) and provided a valuable constraint for how the subducting plate geometry may influence mantle flow proximal to the slab (Buttles and Olson, 1998; Kneller and van Keken, 2007; Zandt and Humphreys, 2008; Jadamec and Billen, 2010; Song and Kawakatsu, 2013). In the warm upper mantle, where A-, C-, or E-type olivine fabric are expected to dominate, the deformation of olivine by dislocation creep can lead to lattice preferred orientation that results in splitting of seismic shear waves, wherein the azimuth of the seismic fast axis tracks the direction of shear within the mantle (Nicolas and Christensen, 1987; Savage, 1999; Tommasi et al., 1999; Kaminiski and Ribe, 2002; Karato et al., 2008; Long and Silver, 2009; Long and Becker, 2010). Away from plate margins, in the center of the oceanic plates, the direction of plate motion and the azimuth of the fast seismic axes measured from shear wave splitting observations tend to be sub-parallel (Becker et al., 2003; Conrad et al., 2007; Kreemer, 2009; Conrad and Behn, 2010), implying simple shearing flow and alignment of the mantle flow field with surface plate motion.

However, near subduction zones, the azimuth of the fast axes of the polarized waves are commonly oriented non-parallel to the direction of local plate motion (Figure 2) (Russo and Silver, 1994; Fischer et al., 1998; Peyton et al., 2001; Smith et al., 2001; Pozgay et al., 2007; Long and Silver, 2008; Abt et al., 2010; Long and Becker, 2010; Hanna and Long, 2012; Long and Wirth, 2013; Long, 2013). This implies that the warm upper mantle proximal to subduction zones locally flows in 
a different direction than the tectonic plates (Long, 2013) and possibly at a greater speed (Conder and Wiens, 2007; Hoernle et al., 2008; Jadamec and Billen, 2010; Stadler et al., 2010).

It is important to point out, that, because the splitting signal is cumulative along the ray-path, teleseismic observations recorded near a subduction zone can include effects from the subslab region, from within the slab, from the cold region of the inner wedge corner, and from the overlying plate, as well as from within the dynamic mantle wedge (Jung and Karato, 2001; Kneller et al., 2007; Faccenda et al., 2008; Hammond et al., 2010; Song and Kawakatsu, 2012). Studies that use local S waves, sourced from within the slab, are thus very valuable in resolving anisotropy of mantle wedge origin, as they do not sample subslab material, and many of these studies do show seismic fast axes oriented in a different direction that surface plate motions, implying the decoupling of motion (Figure 2) (Yang et al., 1995; Fouch and Fischer, 1996; Smith et al., 2001; Audoine et al., 2004; Pozgay et al., 2007; Abt et al., 2010; MacDougall et al., 2012; Long and Wirth, 2013). The local studies will, however, still sample mantle and lithospheric material affected by water, melt, temperature, and discontinuities that can also contribute to the splitting pattern (Savage, 1999; Jung and Karato, 2001; Holtzman et al., 2003; Crampin and Peacock, 2005; Kneller et al., 2007; Karato et al., 2008; Long, 2013). Thus, the ability to quantitatively link the mantle flow field with a specific observed splitting pattern for a given location is still actively being studied.

In geodynamics, there has been a new direction of subduction zone modelling that has explored the three-dimensional nature of mantle flow in subduction zones, motivated in part by the observations from shear wave splitting, but also by the observed variations in slab geometries worldwide. The 3D models show that although the 2D models can provide important physical realism, 2D models cannot capture 
the truly 3D features of the mantle flow field that can occur at subduction zones, due to toroidal flow around slab edges (Stegman et al., 2006; Jadamec and Billen, 2010), lateral changes in slab geometry and buoyancy (Kneller and van Keken, 2007; Capitanio and Faccenda, 2012), small scale convection within the mantle wedge (Honda and Saito, 2003; Wirth and Korenaga, 2012), lateral gravitational instabilities above the mantle wedge (Behn et al., 2007), and lateral changes in thickness of the upper plate (Miller and Becker, 2012; Rodríguez-González et al., 2014). Three-dimensional slab-driven flow can be fundamental to understanding geophysical and geochemical processes in subduction systems (Kneller and van Keken, 2007; Hoernle et al., 2008; Durance et al., 2012). However, incorporating the detailed slab complexities has previously been out of reach of most computational infrastructure and software.

Therefore, one might ask, how feasible is it to model the geometric complexities of plate boundaries and the tectonic processes at slab edges, tears, and triple-junctions? Advances in high-performance computing (HPC) are now allowing for an unprecedented level of detail to be incorporated into numerical models of plate boundary dynamics (Jadamec and Billen, 2010; Stadler et al., 2010; Jadamec et al., 2013; Rudi et al., 2015; Hu et al., 2016). Advances in numerical algorithms combined with the increase in computational resources are allowing high-resolution modelling and the associated examination of three-dimensional, non-linear mantle flow and slab deformation (Zhong et al., 2007; Burstedde et al., 2009; Jadamec and Billen, 2010; Stadler et al., 2010; Burkett and Billen, 2010; Liu and Stegman, 2012; Rudi et al., 2015; Hu et al., 2016). In addition, the coupling of the HPC with immersive 3D data visualisation now allows the user to bring physical meaning to the hundreds of millions of numbers that numerically represent the model, enabling the numerical modeler to grasp the model components as would a laboratory modeler working with a tangible physical construct (Kreylos et al., 2006; Billen et al., 2008; Chen et al., 2008; 
Jadamec et al., 2012).

In this paper, I show examples of this process and demonstrate how the increase

in computational power has enabled a new avenue of geodynamics research, and in 3D geographically referenced regional modelling of slab-driven mantle flow in particular. It is not that having greater computational resources only allows the same model to be run at higher resolution. Rather, the paper posits that with the greater computational resources, new questions can be asked, and hence a new kind of scientific discovery can be conducted in subduction zone research.

\section{Increase in Computing Capabilities Enables a New Direction in Sub- duction modelling}

Ten years ago, the high-resolution 3D regional numerical modelling approach of geographically referenced subduction zones may not have been feasible on a day-today modelling time-frame. Only a limited number of somewhat extreme subduction models utilized the computational resources necessary to run such high-fidelity models, > 17,000 compute hours per model for example (Jadamec and Billen, 2010; Stadler et al., 2010). However, the rapidly changing computational landscape suggests that this form of modelling, although less common, will become commonplace in the next ten years (Keyes et al., 2003).

\subsection{Advances in High Performance Computing}

Figure 3 shows the increase in size of the most powerful super-computer systems worldwide, from 1993-2015 (Strohmaier et al., 2015). The graph shows the total number of cores and Rmax for the top ranked machines over this time period, according to the TOP500 (Strohmaier et al., 2015). The TOP500 list is ranked by performance on the LINPACK Benchmark (Strohmaier et al., 2015), and thus takes 
into account the peak floating point operations (Rmax in Tera-Flops) as well as net number of compute cores (Figure 3). In the early- to mid-1990s, the largest machines were comprised of on the order of 1000 cores. Just after the turn of the century (early 2000s), the size of the largest machines increased to on the order of 10,000 cores, followed by an increase to $\sim 100,000$ s cores in 2005-2010. The largest publically accessible computers now (in 2015) contain over 1 million cores (Figure 3).

The exponential increase in the computational hardware through time is consistent with that predicted by Moore's Law (Keyes et al., 2003). However, it should be pointed out that although one can measure the peak performance on a machine, the code performance for a particular set of software is a function of not only the number of floating point operations, but also the memory bandwidth and the sophistication and portability of the numerical algorithms (Gropp et al., 1999; Keyes et al., 2003). Thus, not all codes run on the largest machines will achieve peak performance. Nonetheless, the increase in computational power will have dramatic effects on not only the scale of problems, but also in terms of the scientific hypotheses that can be posed.

What it means for geodynamics, is a dramatic increase in compute power available for numerical simulations (Jadamec and Billen, 2010; Stadler et al., 2010; Jadamec et al., 2012; Kronbichler et al., 2012; Rudi et al., 2015; Gassmöller et al., 2016). A little more than 10 years ago, a machine consisting of 10,000 cores would have been considered state of the art and using it would have been pushing the envelop of what was possible with subduction modelling (Figure 3). Now that number is 1,000,000 cores (Figure 3). The prospects are exciting; however, without scalable and efficient numerical algorithms the hardware will remain underutilized (Zhong et al., 2015; Rudi et al., 2015; May et al., 2016). Therefore, the interdisciplinary research 
between geodynamics and computational science remains a key step in leveraging the increased computational infrastructure (Keyes et al., 2003; Kronbichler et al., 2012; Rudi et al., 2015).

\subsection{Governing Equations for Viscous Flow modelling}

To provide a framework for the governing equations implemented in the computational fluid dynamics research summarized in this paper, a first order description of the governing equations for solid sate flow in the mantle are described. These equations have been implemented numerically into a number of open source codes that simulate viscous flow of the Earth (King et al., 1990; Moresi and Gurnis, 1996; Tackley, 1996; Zhong et al., 2000; Moresi et al., 2007; Zhong et al., 2007; van Keken et al., 2008; Kronbichler et al., 2012; Lin, 2014). The governing equations for the viscous flow are the conservation of mass, momentum, and energy (Batchelor, 1967; White, 2003). The conservation of mass, also referred to as the continuity equation, can be expressed in differential form for an infinitesimal control volume:

$$
\frac{d \rho}{d t}+\nabla \cdot(\rho \mathbf{V})=0
$$

which, for an incompressible fluid, simplifies to

$$
\nabla \cdot \mathbf{V}=0
$$

where $\nabla$ is the gradient operator, $\mathbf{V}$ is the flow velocity, $\rho$ is density, and $t$ is time (White, 2003). In simple terms, this equation states that the mass flowing into the control volume is equal to the mass flowing out of the control volume.

The conservation of momentum has the following differential form for an infinitesimal control volume:

$$
\rho \mathbf{g}-\nabla p+\nabla \cdot \tau_{i j}=\rho \frac{d \mathbf{V}}{d t}
$$


where

$$
\frac{d \mathbf{V}}{d t}=\frac{\partial \mathbf{V}}{\partial t}+(\nabla \cdot \mathbf{V}) \mathbf{V}
$$

$\mathrm{p}$ is the pressure, $\mathbf{g}$ is the acceleration due to gravity, $\tau_{i j}$ is the viscous stress tensor, and the other components are as described above. Eq. 3 sets the gravity (body) force per unit volume, pressure force per unit volume, and viscous force per unit volume equal to the density times acceleration (Batchelor, 1967; White, 2003).

In modelling the creeping flow of the mantle, we commonly assume an incompressible viscous fluid with a high Prandtl number and Eq. 3 becomes:

$$
\rho \mathbf{g}+\nabla \cdot \sigma_{i j}=0
$$

where the stress, $\sigma_{i j}$, is equal to

$$
\sigma_{i j}=-P \delta_{i j}+\tau_{i j}
$$

and $P$ is the dynamic pressure and the term $\tau_{i j}$ contains the viscosity, $\eta$, and the strain-rate tensor, $\dot{\varepsilon}_{i j}$, and the subscripts, ${ }_{i j}$, refer to the components of the stress and strain rate tensors (Moresi and Solomatov, 1995; White, 2003). Specific viscosity formulations, such as a strain rate dependent viscosity based on experimentally derived flow laws (Hirth and Kohlstedt, 2003; Billen and Hirth, 2007) or directionally dependent mechanically weakening (Lev and Hager, 2011; Sharples et al., 2016), can be used and connected to the force balance through this equation.

In mantle convection it is common to express the initial body force $(\rho \mathbf{g})$ in Eq. 5 in terms of the temperature variation $\left[\rho_{\mathrm{o}} \alpha\left(T-T_{\mathrm{o}}\right)\right]$, wherein $\alpha, \mathrm{T}, \mathrm{T}_{o}$ are the coefficient of thermal expansion, temperature, reference temperature, respectively (Zhong et al., 2007, 2015). In addition to the body force due to density variations as a function of temperature, density variations due to different rock types and phase transitions can be included. These equations can be simultaneously solved to obtain 
the flow velocity, pressure, and viscosity, if the viscosity is also an unknown. Solving the conservation of mass and momentum for viscous flow is typically what is done when the solving the instantaneous problem.

For the time-dependent problem, the conservation of energy is typically also solved in order to allow for the thermal field to move as a function of the viscous flow (White, 2003; Zhong et al., 2007, 2015). For incompressible flow with constant properties and ignoring internal heating and viscous dissipation, the conservation of energy can be simplified to the following differential form

$$
\frac{\partial T}{\partial t}=-\mathbf{V} \cdot \nabla T+\kappa \nabla^{2} T
$$

where $\kappa$ is the thermal diffusivity and $t$ is time, and the other variables are as defined above (White, 2003). Whereas, the temperature, T, is the input in the conservation of momentum equation (Eq. 3), with the conservation of energy (Eq. 7), temperature is the unknown which is solved for. The approximations, assumptions, and simplifications of these equations in a given subduction model will depend in part on the questions asked. It is important to point out that these governing equations are used to examine the solid state flow of the mantle and slab. Additional equations are required to examine the multi-physics flow of magma migration that occurs within the solid state mantle framework of the subduction zone (McKenzie, 1984; Spiegelman, 1993; Katz and Takei, 2013; Wilson et al., 2014).

To simulate subduction and large-scale viscous flow in the mantle, the conservation equations are numerically approximated on a discretized model mesh (Zhong et al., 2007, 2015). The mantle convection codes vary in the numerical approach and use finite difference, finite element, and finite volume schemes most commonly (Zhong et al., 2007, 2015). As complexity, in terms of geometry, rheology, and mineralogy, are added into the numerical models, the role of computational and applied 
mathematics becomes critical as the choice of solvers and internal description and implementation of the problem can greatly affect convergence, model runtime, and scalability (Moresi and Solomatov, 1995; May and Moresi, 2008; Brown et al., 2012; Jadamec et al., 2012; Brune et al., 2015; May et al., 2016).

\section{Incorporating Geometric Complexity into Plate Boundary Models and Leveraging Computational Resources}

Although many open source software packages are available that simulate the viscous flow of the Earth (King et al., 1990; Moresi and Gurnis, 1996; Tackley, 1996; Zhong et al., 2000; Moresi et al., 2007; Zhong et al., 2007; van Keken et al., 2008; Kronbichler et al., 2012; Lin, 2014), there are few open source programs that generate the three-dimensional model input for the viscous flow codes, such that the initial model configuration takes into account the geometric complexity of the earth, on the scale of 2-3 km over a large model domain (Jadamec et al., 2012). This is particularly true for the 3D regional subduction models that use realistic plate geometries, which often contain a complex slab geometry at an arbitrary orientation with respect to the model mesh grid (Billen et al., 2003; Jadamec et al., 2012; Hu et al., 2016). This aim of replicating a particular plate boundary on Earth at high-resolution $(<10$ $\mathrm{km}$ ) in terms of the actual modern plate geometries and 3D lithospheric structure separates the high-resolution geographically referenced 3D regional models from the generalized 3D numerical models of subduction.

For simplified three-dimensional cases, the 3D model set-up can be obtained with a relatively small amount of code and many simplifying assumptions (Kneller and van Keken, 2008). However, the modeler is now faced with representing both (a) slab complexity, including slab edges, tears, and along strike variations in slab dip and depth (Gutscher et al., 2000; Ratchkovski and Hansen, 2002; Lallemand 
et al., 2005; Zhao et al., 2012; Dougherty and Clayton, 2014; Scire et al., 2016), and (b) upper plate complexity, such as lateral variations in thickness, temperature, and composition (Silberling et al., 1994; Van Staal et al., 1998; Greninger et al., 1999; Bird, 2003; Artemieva, 2006; Müller et al., 2008; Hartmann and Moosdorf, 2012; Laske et al., 2013), at a resolution of $<10 \mathrm{~km}$ and with multiple features arbitrarily oriented with respect to the model grid (Jadamec et al., 2012). Thus, more sophisticated approaches are required (Jadamec and Billen, 2010; Liu and Stegman, 2011; Gurnis et al., 2012; Jadamec et al., 2012; Williams et al., 2012; Jadamec et al., 2013; Bower et al., 2013; Heinecke et al., 2014; Bower et al., 2015; Seton et al., 2015; Leonard and Liu, 2016).

For the high-resolution model design, the complex 3D plate boundary configurations must be configured numerically with a computational infrastructure, either a single code or series of codes connected through linked workflows (Kreylos et al., 2006; Jadamec and Billen, 2010; Liu and Stegman, 2011; Gurnis et al., 2012; Jadamec and Billen, 2012; Williams et al., 2012; Heinecke et al., 2014; Bower et al., 2015; Fischer et al., 2015). Thus, for the high-resolution 3D regional models, the model set-up can be challenging and time-consuming. This adds a non-trivial step of model design to the numerical modelling workflow (Figure 4). For this kind of modelling approach, the data collection and pre-processing phase (Figure 5a), model design phase (Figure 5b), and model simulation phase (Figure 5c) can comprise equal parts of the overall modelling effort.

\subsection{Generating Realistic 3D Tectonic Models}

An example of a recent open source $\mathrm{C} / \mathrm{C}^{++}$program that has been successful in building 3D tectonic configurations of geographically referenced plate boundaries is SubductionGenerator (Jadamec and Billen, 2010; Jadamec et al., 2012). A 3D model 
mesh and tectonic configuration are constructed based on a user specified model domain, slab surface, seafloor age grid file, and shear zone surface (Figures 5a,b). The initial 3D thermal structure for the plates and mantle within the model domain is then constructed using a series of libraries within the code that use a half-space cooling model, plate cooling model, and smoothing functions (Jadamec and Billen, 2010; Jadamec et al., 2012). The code maps the initial 3D thermal structure and the 3D plate interface onto the mesh nodes using a series of libraries including a k-d tree to increase efficiency (Jadamec and Billen, 2010; Jadamec et al., 2012). In this way, complicated geometries and multiple plates with variable thickness can built onto a multi-resolution finite element mesh with a 3D thermal structure and 3D isotropic shear zones oriented at any angle with respect to the grid (Figure 5b). The program has been used build 3D configurations for the eastern Alaska subduction-transform system (Jadamec and Billen, 2010, 2012; Jadamec et al., 2013), the Cocos-Nazca slab window (Jadamec and Fischer, 2014), and the New Hebrides subduction-back arc spreading system (Jadamec et al., 2011; McLean et al., 2011).

The three-dimensional thermal structure, plate boundary shear zone, and model mesh can be used as input to finite-element codes that solve for the viscous flow in subduction zones, such as CitcomCU (Moresi and Solomatov, 1995; Zhong, 2006). Specifically, the initial thermal distribution (Figure 5b) can be used as input to the conservation of the momentum equation (Eq. 5) to provide the initial buoyancy forces that drive the flow (Figure 5c). The 3D plate boundary shear zone can be input in the viscous flow calculations through the viscosity formulation and constitutive relation (Eq. 6).

The idea of using geophysical and geologic observations to constrain the initial configuration in geodynamic modelling is not new (Ricard and Vigny, 1989; LithgowBertelloni and Richards, 1998; Becker and O'Connell, 2001; Conrad and Lithgow- 
Bertelloni, 2002; Miller and Becker, 2012). What is new is the level of detail with which this now being done, due the increased computing resources, thus further differentiating regional 3D models from global models and requiring the new approach to model design (Jadamec et al., 2012). The synthesis of detailed global data (Gurnis et al., 2012; Williams et al., 2012) in combination with the use of adaptive mesh refinement (Burstedde et al., 2009) will be invaluable in moving the high-resolution modelling to the global scale and through time.

\section{From 2D to 3D numerical models of subduction}

Before describing the impacts of three-dimensional models of subduction driven solid state mantle flow, it is important to point out that two-dimensional numerical models have, and continue to provide, a tremendous amount of insight, and in and of themselves can still be quite challenging, depending on the scientific problem posed. The progression in 2D modelling of subduction, from 2D corner flow models to models with a free slab and mobile upper plate, is illustrated in Figure 6 with a simplified rendering of three phases in the sophistication of the model set-up. Not all model development is linear, and therefore the figure represents schematically the advances in model componentry, while recognizing that parallel tracts of model development occur. In addition, the progression in modelling magma dynamics with two-phase flow is not illustrated.

The early approach to subduction modelling focused on solving for the corner flow in the mantle wedge, that is mantle flow field in the region between the slab and the upper plate (Figure 6a) (McKenzie, 1969; Sleep and Toksöz, 1971; Tovish et al., 1978). This line of 2D modelling continues, solving for the flow in the mantle wedge with very high-resolution $(<0.5 \mathrm{~km}$ ) (Van Keken et al., 2002; van Keken et al., 2008; Wada et al., 2008; Syracuse et al., 2010). The approach of solving for the 
steady-state corner flow in the mantle wedge has also been applied to 3D modelling and has provided valuable insights into high-resolution $(\sim 2 \mathrm{~km})$, three-dimensional steady-state mantle wedge flow (Kneller and van Keken, 2007; Wada et al., 2015).

Because many slabs bend with increasing depth and therefore do not have a single dip or slab velocity during the subduction evolution (Jarrard, 1986; Lallemand et al., 2005), 2D numerical models of subduction have increased in sophistication to investigate the deformation of the slab, the mantle flow beneath the slab, and the time-dependent flow within the wedge (Figure 6b) (Houseman and Gubbins, 1997; Gerya et al., 2004; Hyndman et al., 2005; Billen and Hirth, 2007; Cížková et al., 2007; Burkett and Billen, 2009; Ribe, 2010; Jadamec, 2016). 3D numerical models have also expanded the model domain and set-up to investigate the 3D deformation of the slab and/or 3D deformation of the surrounding mantle, both below the slab and in the mantle wedge (Zhong and Gurnis, 1996; Piromallo et al., 2006; Stegman et al., 2006; Giuseppe et al., 2008; Jadamec and Billen, 2010; Liu and Stegman, 2012; Faccenda and Capitanio, 2013; Paczkowski et al., 2014).

With increasing model complexity, the numerical models can solve for the lateral motion of a mobile upper plate in addition to the motion of the slab and mantle, in 2D (Figure 6c) (Sharples et al., 2014) and 3D models (Jadamec and Billen, 2010; Capitanio et al., 2011; Jadamec et al., 2013; Schellart and Moresi, 2013). In this way, numerical models can investigate how the upper plate evolution dynamically feedbacks into the slab deformation and subsequent mantle flow field (Figure 6c) (Sharples et al., 2014; Rodríguez-González et al., 2014; Holt et al., 2015).

Accurately incorporating the upper plate, and the corresponding plate interface, in numerical models of subduction remains a challenge (Jadamec et al., 2012). It is still non-trivial to define a rheological formulation that allows for weakening of the plate boundaries and strengthening of the plate interiors, in such a way that 
these features emerge from the dynamics and evolve in space and time with the subduction zone forces (Regenauer-Lieb et al., 2001; Kaus and Podladchikov, 2006; Crameri et al., 2012; Bercovici and Ricard, 2014; Sharples et al., 2016).

Among the 3D numerical models of subduction, there are a subset that incorporate a complex and detailed 3D slab geometry based on seismic observations into the mantle domain, e.g., Moresi and Gurnis (1996). The approach therein is to use the high-resolution numerical models of a particular region as a way to constrain the subduction processes, rather than running a suite of models with general slab shapes and mantle properties (Figures 4 and 5). This has been done for the Mariana, Izu-Bonin, Japan, and South Kurile subduction zone (Moresi and Gurnis, 1996), the Tonga-Kermadec subduction zone (Billen et al., 2003; Billen and Gurnis, 2003), the Aleutian oceanic-oceanic subduction zone (Billen and Gurnis, 2003), and the oceanic-continent subduction zone in eastern Alaska (Jadamec and Billen, 2010, 2012; Jadamec et al., 2013). More recent high-resolution 3D numerical models of specific subduction zones include the evolution of slab rupture and upper mantle flow in western North America (Liu and Stegman, 2012), and the three-dimensional mantle flow through the Patagonia slab window in South America (Lin, 2014), the reversal of mantle flow through the Cocos-Naza slab window beneath the western Caribbean plate (Jadamec and Fischer, 2014), and the intersection of slabs beneath the Taiwan subduction system (Lin and Kuo, 2016).

A high-resolution geographically referenced regional 3D model, solving for the subslab flow as well as upper mantle flow and slab deformation, can commonly contain over 100 million mesh nodes, over 500 million unknowns, have a local resolution of $2.5 \mathrm{~km}$, and cost 15,000 - 20,000 compute hours per time-step (Jadamec and Billen, 2010, 2012; Jadamec et al., 2013). A fine resolution over a large portion of the plate boundary is required to resolve the geometric complexity as well as the 
viscosity variations ( $\sim 7$ orders of magnitude) that dynamically emerge due to a strain-rate dependent rheology. In other words, the mesh needs to be discretized sufficiently to resolve variations in viscosity occurring between the relatively strong lithospheric plates $\left(\sim 10^{22}-10^{25} \mathrm{~Pa}\right.$ s) and the weaker plate interface $\left(\sim 10^{18}-10^{22} \mathrm{~Pa}\right.$ s) and weak mantle wedge $\left(\sim 10^{17}-10^{18} \mathrm{~Pa} \mathrm{~s}\right)$, wherein the net change in viscosity occurs over spatial distances on the order of $100 \mathrm{~km}$ or less and this change needs to transition smoothly for numerical stability (Moresi and Solomatov, 1995; Tackley, 1996; Jadamec et al., 2012). With adaptive mesh refinement, this high-resolution 3D slab and upper mantle non-linear modelling approach is being extended to the global scale (Stadler et al., 2010; Alisic et al., 2012; Kronbichler et al., 2012; Rudi et al., 2015).

\section{Recent Results of slab-driven Mantle Flow from 3D Subduction Models}

As posited earlier, a question to ask with high resolution 3D regional modelling of subduction systems is, do we really learn anything new; are new processes discovered, or just the same process resolved at higher resolution? In this section, I give examples of general tectonic processes at plate boundaries discovered or at least better characterized as a result of the high resolution 3D regional modelling approach. The section begins with a characterization of the mantle flow field determined from generalized 3D numerical models of subduction, and then highlights three processes related to slab-driven mantle flow for which the high resolution 3D models have particularly contributed to our understanding. The section will draw more heavily on my models, as those are the models with which I have the most experience and are a good example of the kind of capability and flexibility of the approach discussed in this paper and of the new kinds of results discovered. In some cases, I will highlight 
results from 3D laboratory models, as these are increasing in level of sophistication and have been a valuable constraint on the numerical models.

\subsection{General Patterns of Slab-driven 3D Mantle Flow}

Three-dimensional numerical models of subduction indicate a departure from the paradigm of corner flow in subduction zones. Although the slab descent into the mantle does drive corner flow in the mantle wedge drawing mantle toward the slab and then entraining mantle downward as the slab sinks further downward (Figure 7a), $3 \mathrm{D}$ geodynamic models indicate that this is just one component of the mantle flow field in subduction zones (Figure 7b-f) (Piromallo et al., 2006; Royden and Husson, 2006; Stegman et al., 2006; Conder and Wiens, 2007; Kneller and van Keken, 2007; Schellart et al., 2007; Faccenna et al., 2010; Jadamec and Billen, 2010; Capitanio and Faccenda, 2012).

Specifically, in addition to the slab-driven corner flow which is confined to within a cross section through the subduction zone (Figure 7a), lateral changes in the dip and buoyancy of the slab as well as in the mantle wedge viscosity can drive arc-parallel flow in the mantle wedge (Conder and Wiens, 2007; Kneller and van Keken, 2007; Jadamec and Billen, 2010; Capitanio and Faccenda, 2012; Jadamec and Billen, 2012) and in the subslab mantle (Jadamec and Billen, 2010; Capitanio and Faccenda, 2012; Jadamec and Billen, 2012) with mantle material moving perpendicular to the cross section plane (Figure 7b). 3D instantaneous models with a slab edge show that slab steepening can drive toroidal flow, wherein subslab mantle is transported around the side of a lateral slab edge and into the mantle wedge (Figure 7c) (Piromallo et al., 2006; Jadamec and Billen, 2010, 2012). Time-dependent 3D numerical models with a slab edge show that this process evolves over time with the trench retreat and slab rollback driving toroidal flow around the lateral slab edges that varies in its intensity 
over the lifetime of the subduction zone (Stegman et al., 2006; Schellart et al., 2007; Faccenna et al., 2010). The 3D models with a slab edge that is free to change dip show that as the mantle material sweeps around the lateral slab edge there is commonly an upwelling component to the flow that transports subslab mantle upwards (Figure 7c) (Stegman et al., 2006; Piromallo et al., 2006; Jadamec and Billen, 2010; Faccenna et al., 2010; Jadamec and Billen, 2012). Tearing of a viscous slab can facilitate mantle upwelling through and along the slab tears (Burkett and Billen, 2010; Liu and Stegman, 2012) (Figure 7d). Three-dimensional mantle wedge flow can also occur due to structure in the mantle wedge (Honda and Saito, 2003; Conder and Wiens, 2007), structure in the upper plate (Behn et al., 2007; Miller and Becker, 2012; Rodríguez-González et al., 2014), or motions in the upper plate (Hall et al., 2000). In addition, the slab-driven toroidal flow can in turn drive overriding plate deformation through mantle tractions on the base of the overriding plate (Capitanio et al., 2011; Schellart and Moresi, 2013; Menant et al., 2016) (Figure 7f).

Thus, recognizing the three-dimensional nature of the mantle flow field in subduction zones was a fundamental milestone that significantly affected the perception and conceptualization of subduction processes and numerical modelling (Hall et al., 2000; Conder and Wiens, 2007; Kneller and van Keken, 2007; Schellart et al., 2007; Jadamec and Billen, 2010; Capitanio et al., 2011; Liu and Stegman, 2012). It is important to point out that laboratory models played a critical role in characterizing this new three-dimensional paradigm for slab-driven mantle flow (Buttles and Olson, 1998; Kincaid and Griffiths, 2003; Funiciello et al., 2004; Schellart, 2004; Bellahsen et al., 2005; MacDougall et al., 2014; Strak and Schellart, 2014). The laboratory models provided an invaluable framework for the 3D numerical modelling studies and made the first attempts to explain the shear wave splitting observations in a 3D model (Buttles and Olson, 1998). In addition, the 3D laboratory models were 
critical in first identifying the time-dependent 3D variations in trench geometry, slab dip, and slab-driven mantle flow, and in categorizing the time-dependent phases of subduction from the initial transient phases to the established modes of trench retreat and slab rollback after the slab is laid flat on the lower mantle, for example (Funiciello et al., 2004; Schellart, 2004).

\subsection{Slab-driven Mantle Upwelling at Slab Edges}

An interesting component of the mantle flow field in subduction zones revealed by the 3D subduction modelling is the slab-driven mantle upwelling at slab edges (Figure 7). The fluid flow pattern of toroidal flow around a pivoting structure is expected from general fluid dynamics principles (Batchelor, 1967). In the subduction zone, at a lateral slab edge, as the slab steepens or rolls back, the subslab mantle material is pushed by the moving slab and is translated around the lateral slab edge into the mantle wedge, e.g., Stegman et al. (2006). This forms the arcuate toroidal flow pattern seen in depth slices of mantle flow velocity in 3D subduction models with slab edges (Figures 7 and 8b) (Jadamec and Billen, 2010).

Associated with this toroidal flow, is an upwelling component in the mantle, such that, as the arcuate toroidal flow field moves material laterally around the slab edge, warm mantle is also transported from underneath the slab into the lower pressure mantle wedge in an upward and arcuate pattern around the edge (Figures 7 and 8b) (Piromallo et al., 2006; Jadamec and Billen, 2010). There is a combination of the slab steepening which pushes material behind the slab causing it to move laterally around the slab edge, e.g., Stegman et al. (2006), and the low dynamic pressure that is created above the slab, e.g., Manea and Gurnis (2007); Hu et al. (2016), that draws asthenosphere upwards into the mantle wedge. The zone of mantle upwelling typically occurs lateral to the slab edge, located within $500 \mathrm{~km}$ outboard of the slab 
edge (Piromallo et al., 2006; Jadamec and Billen, 2012). The upward component of mantle flow associated with toroidal-type return flow was first recognized in 4D (time-dependent 3D) laboratory models of subduction (Schellart, 2004), and has since been demonstrated in both laboratory and numerical models (Piromallo et al., 2006; Faccenna et al., 2010; Guillaume et al., 2010; Jadamec and Billen, 2010, 2012; Liu and Stegman, 2012; Strak and Schellart, 2014, 2016). The slab edge driven mantle upwelling may lead to melting and volcanism that is distinct from typical arc volcanism associated with corner flow in the mantle wedge.

Regional 3D numerical models can help to constrain this process through the ability to spatially link the predicted mantle upwelling with the location of observed slab derived melts, such as adakites. Adakitic volcanics reflect a range in petrogenetic origins (Kay, 1978; Drummond et al., 1995; Yogodzinski et al., 1995; Kay and Kay, 2002; Kelemen et al., 2003; Castillo, 2012), including the association with slab melting in subduction zones of either young oceanic material or otherwise warmed oceanic material (Defant and Drummond, 1990; Johnston and Thorkelson, 1997; Abratis and Worner, 2001; Durance et al., 2012). In the Alaska subduction zone, for example, the Wrangell volcanics are located east of the main Aleutian-Alaska magmatic arc and are situated east of a major break in slab seismicity indicative of the slab edge (Ratchkovski and Hansen, 2002; Jadamec and Billen, 2010). The Wrangell volcanics display a range in morphologies from strato-volcanoes to shield-like edifaces and are characterized by a range in geochemical signatures including, adakitic affinities suggestive of melting of the edge of the subducted Pacific plate (Skulski et al., 1991; Preece and Hart, 2004; Trop et al., 2012).

Recent geographically referenced, 3D regional models of the Alaska subduction zone, with a local resolution of $2.5 \mathrm{~km}$, tested the effect of high-resolution slab geometry on the mantle flow field beneath mainland Alaska, including in the vicinity 
of the Wrangell volcanics (Jadamec and Billen, 2010; Jadamec et al., 2011; Jadamec and Billen, 2012). These 3D instantaneous numerical models predicted upwelling associated with the toroidal flow around the eastern slab which entrained warm mantle material in a three-dimensional upward flow pattern, with the location of the Wrangell volcanics above the upward stroke of the 3D flow field (Figure 8b) (Jadamec and Billen, 2010; Jadamec et al., 2011; Jadamec and Billen, 2012). In addition, geographically referenced, 3D high-resolution (local resolution of $\sim 3 \mathrm{~km}$ ) models of the Cocos-Nazca slab window also show slab edge related upwelling associated with the arc of the toroidal flow around both the southern Cocos and the northern Nazca slab edges (Figure 9) (Jadamec and Fischer, 2014). This upward motion entrains warmed asthenospheric mantle and warmed slab edge material upwards and thus could contribute to the observed anomalous volcanism in southern Central America (Defant and Drummond, 1990; Johnston and Thorkelson, 1997; Abratis and Worner, 2001).

This detailed approach of modelling the slab-driven mantle flow field and linking the solid state flow framework with the resultant movement of geochemical signatures through out the subduction system remains an important future direction in subduction modelling (Jadamec and Billen, 2010; Schellart, 2010; Durance et al., 2012; Jadamec and Billen, 2012; Lin, 2014), particularly in the time-dependent evolution of the subduction system (Liu and Stegman, 2012; Bower et al., 2015; Hu et al., 2016).

\subsection{Slab-driven Mantle Deformation Zones and Laterally Variable Plate-Mantle Cou-} pling

Another area of research where 3D high-resolution regional models have made a contribution is in constraining the slab and upper mantle viscosity, and in placing 
constraints on lateral variability in plate-mantle coupling (Figure 10). Although the average upper mantle viscosity is the order of $10^{20} \mathrm{~Pa} \cdot \mathrm{s}$, as determined from post-glacial rebound and global velocity models (Hager, 1991; Mitrovica and Forte, 2004), experimental studies suggest the viscosity in the mantle wedge may be several orders of magnitude lower, $\sim 10^{18} \mathrm{~Pa} \cdot \mathrm{s}$ (Hirth and Kohlstedt, 2003; Karato, 2003). The local reduction in mantle wedge viscosity is likely due to a number of factors including increased temperature, water content, melt-fraction, and strain-rate (Hirth and Kohlstedt, 2003; Karato, 2003; Kelley et al., 2006; Wade et al., 2008). Both 2D and 3D geodynamic models have constrained and continue to constrain these properties (Katz et al., 2003; Billen and Gurnis, 2001; Kincaid and Griffiths, 2003; Billen and Hirth, 2005; Hyndman et al., 2005; Currie and Hyndman, 2006; Cagnioncle et al., 2007; Conder and Wiens, 2007; Wade et al., 2008; Jadamec and Billen, 2010; Syracuse et al., 2010; Lev and Hager, 2011; Wirth and Korenaga, 2012; Wada et al., 2015), and in turn provide a range of testable viscosities in the upper mantle region of the subduction zone.

For example, 3D regional numerical models of the Tonga-Kermadec subduction zone and the Aleutian subduction zone using a Newtonian viscosity found a better fit to the geoid and dynamic topography by imposing a region of low viscosity in the mantle wedge within the Newtonian viscosity models (Billen et al., 2003; Billen and Gurnis, 2003). More recently, geographically referenced, high-resolution 3D geodynamic models of the Alaska subduction zone (local resolution of $\sim 3 \mathrm{~km}$ ) compared the effect of an experimentally derived flow law for diffusion creep (Newtonian viscosity) versus the effect of both diffusion and dislocation creep (composite non-Newtonian viscosity) and found a better fit to shear wave splitting observations, plate motions, and dynamic topography in models using the composite viscosity (Figures 8 and 10) (Jadamec and Billen, 2010; Jadamec et al., 2012; Jadamec and Billen, 2012; Jadamec 
et al., 2013). Importantly, the models found that the non-Newtonian viscosity led to lateral viscosity variations that naturally emerged in the upper mantle beneath Alaska, with a dynamically reduced mantle wedge viscosity $\left(\sim 10^{18}\right.$ to as low as $\sim$ $\left.10^{17} \mathrm{~Pa} \cdot \mathrm{s}\right)$ and reduced subslab viscosity $\left(\sim 10^{18} \mathrm{~Pa} \cdot \mathrm{s}\right)$ that evolved in the model due to the high strain rates surrounding the slab (Figures 10a,b) (Jadamec and Billen, 2010; Jadamec et al., 2012; Jadamec and Billen, 2012).

This dynamically induced zone of low viscosity in the upper mantle surrounding the slab has also been predicted in 2D (Billen and Hirth, 2005; Andrews and Billen, 2009; Jadamec, 2016), generalized 3D (Billen and Jadamec, 2012; Hines and Billen, 2012), and global subduction models (Stadler et al., 2010; Alisic et al., 2012) that incorporate a composite viscosity and examine how the dislocation creep deformation mechanism allows for dynamic weakening of the upper mantle in regions of high strain-rate both above and below the slab. The concept of slab-driven mantle deformation zones and laterally variable plate-mantle coupling in subduction zones has been suggested conceptually by earlier seismological studies that examined misalignment of the seismic fast axes observed from shear wave splitting with the local plate motions, e.g., Russo and Silver (1994). Subsequent studies of shear wave splitting in the mantle wedge constrained by local $\mathrm{S}$ waves as well as teleseismic studies suggest the non-alignment of the mantle flow field with the subducting plate velocity may occur in many subduction zones, e.g., Long and Wirth (2013) and references therein, (Figure 2).

Thus, both the 3D geodynamic models and seismic observations imply local decoupling of the mantle wedge from the surface plates near subduction zones (Figures 2 and $8 \mathrm{a}-\mathrm{c})$. It is important to note that dislocation creep is the same mechanism responsible for (a) the reduced upper mantle viscosity surrounding the slab that emerges in the geodynamic models described here and (b) the lattice preferred ori- 
entation (LPO) in the olivine, that gives rise to the seismic fabric in the upper mantle where olivine is the dominant constituent, assuming the LPO aligns with the mantle flow in regions of high strain rate (Savage, 1999; Karato et al., 2008; Long and Becker, 2010; Jadamec and Billen, 2010). Thus, the zones of (a) slab-driven reduced mantle viscosity and (b) slab-driven mantle flow and associated complex shear wave splitting should be correlated (Jadamec, 2016), if the splitting is due to the LPO developed in olivine in regions of high strain rate aligned with the flow (Figure 2 and Figures 8-10). Away from the subduction zone, the effects of the driving force of the slab decrease, and hence there is a lateral increase in the upper mantle viscosity. The net result is a region of plate-mantle decoupling close to the subduction zone that transitions outwards to more coupling between the plates and mantle and hence more alignment of the flow with surface plate motions farther from the slab (Figure 10) (Jadamec and Billen, 2010; Jadamec, 2016).

High-resolution geographically referenced 3D models can be useful in constraining the length scale of this decoupling zone through the comparison of the predicted upper mantle deformation with observations of shear wave splitting from specific locations on Earth, e.g., Jadamec and Billen (2010) (Figure 8). The width of the this decoupling zone seems to be on the order of a few hundred kilometers in the lateral and radial directions away from the slab, but is still being studied in both 3D (Jadamec and Billen, 2010; Faccenda and Capitanio, 2012) and 2D models (Jadamec, 2016), and is an active area of research.

The quantitive connection between shear wave splitting observations and the mantle flow field predicted in global, generalized 3D, and regional 3D models has the potential to place a critical constraint on processes that govern the upper mantle flow field near subduction zones. Although there has been work toward this end, predicting LPO, infinite strain axes, finite strain ellipses and synthetic splitting from 
geodynamic models (Hall et al., 2000; Kaminski et al., 2004; Conrad et al., 2007; Kneller and van Keken, 2007; Jadamec and Billen, 2010; Miller and Becker, 2012; Faccenda and Capitanio, 2013), a comprehensive geodynamic-seismic framework may still be in its infancy. A multi-faceted approach will be critical, wherein generalized models make predictions for deformation fabric and splitting (Faccenda and Capitanio, 2012; Di Leo et al., 2014; Li et al., 2014), and then geodynamic models of specific areas are constructed to try to match the splitting patterns and length scales in specific subduction zones (Hall et al., 2000; Fischer et al., 2000; Conder and Wiens, 2007; Kneller and van Keken, 2007; Jadamec and Billen, 2010; Miller and Becker, 2012).

\subsection{Slab-driven Mantle Flow and Mantle Flow Rates}

High-resolution 3D models have also made new strides in placing constraints on mantle flow rates in subduction zones (Jadamec and Billen, 2010; Stadler et al., 2010). The slab strength and upper mantle viscosity place a first order control on the rate at which the slab can drive mantle flow during subduction (Alisic et al., 2012; Billen and Jadamec, 2012; Jadamec and Billen, 2012). The models produce a domain of localized fast asthenospheric flow in the mantle surrounding the slab that is likely to occur at many subduction zones (Figure 10).

For example, the high-resolution 3D regional models of the Alaska subduction zone that tested the relative effect of a Newtonian versus composite viscosity, slab strength, and slab edge geometry and found that models with a composite viscosity were a better fit to shear wave splitting observations, Pacific plate motion, and patterns of subsidence and uplift in the upper plate (Jadamec and Billen, 2010, 2012; Jadamec et al., 2013), also predicted mantle flow rates an order of magnitude greater than surface plate motions for the part of the asthenospheric mantle close 
to the subducting slab (Figures 8 and 10). The models showed that although the surface motion of the plates may be on the order of 1-10 cm/yr, the asthenospheric mantle beneath the plates can flow an order of magnitude faster (up to $\sim 80 \mathrm{~cm} / \mathrm{yr}$ ) in regions of reduced viscosity surrounding the slab (Jadamec and Billen, 2010; Jadamec et al., 2012; Jadamec and Billen, 2012).

The increased asthenospheric velocities close to the subduction zone are due in part to the slab induced mantle weakening and reduced viscous support of the slab (Figures 8 and 10) (Jadamec and Billen, 2010; Jadamec et al., 2012; Jadamec and Billen, 2012). Reducing the viscous support of the slab, requires the slab to support more of its own weight which can lead to plastic failure in the slab hinge, allowing for slab steepening and slab induced rapid mantle flow (Figures 8, 10, and 11). The dynamic viscosity reduction and related rapid mantle flow are also observed in global models that use a strain-rate dependent viscosity, with adaptive mesh refinement allowing for high-resolution at the subduction zones (Stadler et al., 2010; Alisic et al., 2012), as well as in generalized 3D models (Billen and Jadamec, 2012; Hines and Billen, 2012) and in 2D models that vary the slab strength and upper mantle rheology (Figure 11) (Jadamec, 2016).

Rapid mantle flow rates have also been suggested independently by geochemical arguments based on the timing of the emergence of geochemical signatures in the volcanic front in Costa-Rica and Nicaragua (Hoernle et al., 2008) and in the New Hebrides subduction zones (Heyworth et al., 2011). The toroidal flow around slab edges has been shown to lead to increased mantle velocities in the mantle wedge by laboratory models that use temperature dependent glucose syrup (Kincaid and Griffiths, 2003), which numerical models indicate are even faster when using a strainrate dependent viscosity formulation (Jadamec and Billen, 2010; Stadler et al., 2010). This may contribute to the preservation of primitive magmas brought to the surface 
at slab edges and slab edge-back arc spreading intersections, such as in the eastern New Hebrides slab edge region (Figure 12) (McLean, 2010; Jadamec et al., 2011; Durance et al., 2012).

This is a significant departure from the paradigm of the subduction framework predicted by $2 \mathrm{D}$ and 3D models that fix the surface velocity and dip of the slab and solve only for flow in the mantle wedge (Kneller and van Keken, 2007; van Keken et al., 2008; Syracuse et al., 2010; Wada et al., 2015). A model that does not allow the slab to pivot or change velocity (Kneller and van Keken, 2007; van Keken et al., 2008; Syracuse et al., 2010; Wada et al., 2015) would not predict rapid flow because the boundary condition on the slab surface and the inability of the slab to pivot restricts the mantle flow rates in the mantle wedge (King, 2001; Jadamec, 2016). The steady state models are certainly valuable, and provide important insights. A series of $2 \mathrm{D}$ subduction models with a fixed slab dip, but that systemically vary the slab inclination from model to model (Syracuse et al., 2010), could provide insights to how the mantle flow field at a given location might evolve, as the different dips meant to represent different locations could theoretically represent different snapshots of one subduction zone through time. However, the models would not capture the nonsteady state part of the flow where the transition in slab dip occurs and induces the more rapid flow rates.

This interesting phenomenon of rapid mantle flow in subduction zones is simply a function of the system balancing the resisting and driving forces and is not due to model side walls being too close or some complication of the 3D model setup. There are no lateral sidewalls in a global models that show this result (Stadler et al., 2010; Alisic et al., 2012). Furthermore, simplified 2D models, with sidewalls that are over 5-8 times farther away than the length-scale of the slab, demonstrate this force balance as well (Figure 11) (Jadamec, 2016). Thus, the description of the 
rapid mantle flow field surrounding the slab largely came out of 3D models trying to explain processes in a specific geographic location on Earth (Conder and Wiens, 2007; Jadamec and Billen, 2010; Stadler et al., 2010; Alisic et al., 2012; Jadamec and Billen, 2012; Jadamec and Fischer, 2014). A key implication of this result is the importance in constraining the upper mantle rheology and slab strength, as these two parameters play a fundamental role in modulating the flow rates (Andrews and Billen, 2009; Alisic et al., 2012; Billen and Jadamec, 2012; Jadamec and Billen, 2012; Jadamec, 2016).

\section{Discussion}

In Geodynamics, processes occur over a broad range in spatial scales (nanometer to thousands of kilometers), time-scales (seconds to billions of years), and are commonly governed by non-linear material behavior (Kellogg et al., 2008). In addition, unlike in modelling idealized media, the Earth is inherently heterogeneous giving rise to complexity in geometry as a common-place phenomenon (Li et al., 2008; Hayes et al., 2012). The 3D subduction models here have shown how complexity in the geometry of the plate boundary can direct and guide mantle flow within the subduction zone (Kneller and van Keken, 2007; Jadamec and Billen, 2012; Paczkowski et al., 2014). In addition, the models illustrate how processes at the grain scale such as dislocation creep can have a large effect on the morphology of mantle flow at the kilometer scale (Jadamec and Billen, 2010; Stadler et al., 2010). The increase in computational resources combined with advances in numerical algorithms has allowed the modelling of high-resolution, three-dimensional, non-linear mantle flow and slab deformation (Jadamec and Billen, 2010; Stadler et al., 2010; Burkett and Billen, 2010; Rudi et al., 2015). This next section discusses implications of this approach and looks ahead to future directions in 3D subduction modelling. 


\subsection{Moving from the 2D Subduction modelling Paradigm} to 3D Subduction System modelling

With increased computational resources and advanced numerical algorithms, subduction modelling is moving toward subduction system modelling (Govers and Wortel, 2005; Jadamec and Billen, 2010; Lin and Kuo, 2016). In other words, rather than examining a single subducting plate, 3D models are now examining the slab structure in more detail, including multiple subducting plates (Jadamec and Fischer, 2014; Lin, 2014; Lin and Kuo, 2016), allowing for complex slab-upper plate interactions (Jadamec et al., 2013; Malatesta et al., 2013; Rodríguez-González et al., 2014), and modelling the termination of subduction zones into other plate boundary types (Govers and Wortel, 2005; Jadamec and Billen, 2010).

It is important to emphasize that many subduction zones on Earth are not isolated features. Modern subduction zones are discontinuous and terminate into other subduction zones or into transform or spreading centers, making lateral slab edges actually a common feature (Figure 1) (Gudmundsson and Sambridge, 1998; Bird, 2003; Syracuse and Abers, 2006; Hayes et al., 2012). Examples include the subduction termination into (a) a transform boundary, as in eastern Alaska and Cascadia, (b) a spreading center, as in the eastern New Hebrides and the Scotia subduction zones, or (c) into another subduction zone forming a right angle or some other complicated juncture, as in the Aleutian-Kamchatka junction or the Japan-Izu-Nankai triple junction (Gudmundsson and Sambridge, 1998; Bird, 2003; Syracuse and Abers, 2006; Müller et al., 2008; Schellart et al., 2011; Hayes et al., 2012). The lateral portions of the subduction zones and related double and triple junctions, although a pervasive feature of subduction zones, tend to be less studied, modeled less frequently, and hence less understood (Casey and Dewey, 1984; Govers and Wortel, 2005; Wortel et al., 2009; Jadamec and Billen, 2010; Gerya, 2011; Patriat et al., 2015; Lin and 
Kuo, 2016).

Therefore, there is much to be learned from how the slab and mantle respond to plate boundary intersections. This cannot be achieved by modelling flow within the mantle wedge alone (Kneller and van Keken, 2007), rather the mantle wedge as well as subslab flow must be solved for (Schellart et al., 2007), and the slabs must be able to interact with the subslab mantle (Jadamec and Billen, 2010; Capitanio and Faccenda, 2012; Faccenda and Capitanio, 2013) and with each other (Lin and Kuo, 2016) or features in the upper plate (Jadamec et al., 2013; Capitanio, 2014; Rodríguez-González et al., 2014). In particular there are interesting implications for magmagenesis (Jadamec and Billen, 2010; Liu and Stegman, 2012; Menant et al., 2016). For example, the contribution of slab derived melts would be expected if warm mantle is upwelling adjacent to the slab edge, particularly if the slab edge intersects with the subduction zone back arc spreading center or ridge system in the overriding plate, such as in the eastern New Hebrides, southern Marianas, and Scotia subduction zones (Figures 1 and 12) (Defant and Drummond, 1990; Durance et al., 2012; Patriat et al., 2015)

Quantitatively linking the solid state creeping flow of the mantle in 3D with 3D melt migration is an important and complex process and an active area of research. Geographically referenced high-resolution modelling of specific subduction zones can directly address specific hypotheses for a given region, which is a different approach than that of generalized 3D models with a generic geometry (Jadamec and Billen, 2012; Jadamec et al., 2013). In order to study specific areas, the numerical models need high resolution, not only to resolve the detailed slab geometry but also to resolve the multi-phase flow if magma melt and migration are to be incorporated in a truly three-dimensional fashion. However, incorporating magma dynamics greatly complicates the solver because of the hyperbolic systems associated with the poros- 
ity field, as well as more complicated nonlinearities in the conservation equations (Spiegelman, 1993; Katz and Takei, 2013; Wilson et al., 2014). These future highresolution 3D regional multi-phase models will be computationally challenging but also scientifically rewarding in elucidating the underlying physical mechanisms for complex subduction phenomena. This will require a comprehensive subduction system modelling approach, rather than disparate mantle wedge, magma migration, and solid state flow framework models run individually.

\subsection{Constraining Slab Structure from Regional 3D Geodynamic Models}

Because high resolution regional models are geographically referenced and can incorporate entire portions of the subduction zone $(>1000 \mathrm{~km})$ and asthenosphere with local resolution of $2-3 \mathrm{~km}$, the models can test the effect of incorporating different detailed slab geometries and thus help to distinguish between hypothesized slab structures where seismic data are lacking or limited. Qualitatively comparing a mantle flow field produced by a generalized geodynamic model to shear wave splitting patterns from a specific geographic location on earth can be thought provoking and valuable in generating ideas (Zandt and Humphreys, 2008). However, the geodynamic models show that the scale and intensity of the toroidal flow will depend on the density contrast, viscosity ratio, and component dimensions (Stegman et al., 2006; Piromallo et al., 2006; Jadamec and Billen, 2010; Faccenda and Capitanio, 2012). Therefore, in order to match a given shear wave splitting pattern to the mantle flow field in a particular subduction zone, for example, high-resolution 3D models that incorporate detailed slab structure and mantle properties become necessary, as does the calculation of the LPO or some measure of crystal deformation for the given flow field (Jadamec and Billen, 2010) and synthetic splitting (Miller and Becker, 2012).

For example, 3D instantaneous models of the Alaska subduction zone tested two 
different morphologies for the eastern slab edge (Jadamec and Billen, 2010, 2012). The models were geographically referenced, contained over 100 million finite element nodes with a variable mesh resolution as fine as $\sim 2.5 \mathrm{~km}$, and run for $\sim 17,000$ compute hours per model (Jadamec and Billen, 2010, 2012). In this region, the seismic data indicated an ambiguous morphology for the slab edge where the Aleutian megathrust terminates into the Queen Charlotte-Fairweather transform fault system (Page et al., 1989; Ratchkovski and Hansen, 2002; Eberhart-Phillips et al., 2006). Testing two different slab morphologies, the geodynamic models produced very different locations for the toroidal flow, that were over $500 \mathrm{~km}$ apart depending on the slab edge morphology (Figure 8) (Jadamec and Billen, 2010, 2012). By comparing the infinite strain axes produced from the different mantle flow fields to observations from shear wave splitting, a preferred slab shape beneath eastern Alaska was identified (Jadamec and Billen, 2010).

In another example, high-resolution geographically referenced 3D models CocosNazca slab window tested the effect of a continuous slab versus a slab gap on the rate and direction of the mantle flow through the slab window, thus providing constraints on the modern configuration of the Cocos-Nazca slab window (Jadamec and Fischer, 2014) (Figure 9). Recent 3D geodynamic models have also tested the complicated slab intersection beneath Taiwan and the predicted mantle flow and mantle fabric deformation (Lin and Kuo, 2016). Thus, in this way the high-resolution regional models can help to constrain the slab geometry where seismic imaging is limited. This is an important direction in subduction modelling and could benefit from more sophisticated data assimilation techniques and inversion methods (Liu et al., 2008; Liu and Stegman, 2012; Baumann and Kaus, 2015). 


\subsection{Slab-driven Three-dimensional Upper Plate Motion}

Although this paper has mostly focused on scientific investigations of slab morphology and mantle flow in subduction zones, a 3D model set-up that has high enough resolution to resolve the detailed slab morphology is also in a position to examine how the regional slab morphology controls deformation in the overriding plate (Jadamec and Billen, 2010; Jadamec et al., 2013). In particular, because of the high resolution, geographically referenced models of this kind can examine the flat slab subduction processes, such as how the flat slab couples into deformation of the overriding plate in 3D for a particular location on Earth.

A limiter of investigating how the overriding plate is affected by flat slab subduction has been the resolution required to resolve the overriding plate, plate interface, slab, and subslab mantle, as well as how to represent the rheology of the plate interface (Jadamec et al., 2012; Bercovici and Ricard, 2014; Sharples et al., 2014; Holt et al., 2015). 3D numerical models have examined the dynamics of flat slab subduction (Mason et al., 2010; van Hunen and Allen, 2011; Manea et al., 2012; Taramón et al., 2015; Hu et al., 2016) and explored the effects of plateaus and oblique subduction on along strike transport of upper plate material, e.g. Jadamec et al. (2013); Malatesta et al. (2013); Capitanio (2014); Moresi et al. (2014).

Not all flat slabs have the same morphology (Jarrard, 1986; Gutscher et al., 2000; Lallemand et al., 2005; Syracuse and Abers, 2006; Hayes et al., 2012). In some cases the flat slab portion can occur at deeper depths such that it occurs beneath a thick upper plate $(\sim 100 \mathrm{~km})$, as in parts of northern Peru and Chile (Gutscher et al., 2000). Whereas in other cases, the flat slab segment occurs a shallower depths, such as in the Alaska subduction zone and in Columbia (Gutscher et al., 2000; Ratchkovski and Hansen, 2002; Jadamec and Billen, 2010). For cases like this, the upper plate is thin $(<50 \mathrm{~km}$ thick), and the thin region extends laterally for up to 500 
km inboard from the trench (Gutscher et al., 2000; Ratchkovski and Hansen, 2002; Gudmundsson and Sambridge, 1998; Jadamec and Billen, 2010; Hayes et al., 2012). Computationally, this means the geodynamic model must have enough resolution to resolve a thin upper plate, plate interface, and top of the slab within less than 50 $\mathrm{km}$ of the model surface. A global model with resolution of $100 \mathrm{~km}, 50 \mathrm{~km}$ or even $25 \mathrm{~km}$ could not resolve this plate interaction. Conversely, a mantle wedge model with 10 meter resolution, would not extend below the slab and therefore could not incorporate the effects of subslab mantle flow.

Therefore, by including resolution on the order of 2-3 km, in geographically referenced 3D regional models, one can begin to quantitatively explore how the flat slab drives three-dimensional deformation in the upper plate from below (Jadamec et al., 2013; Haynie and Jadamec, In Review 2016). This is a different approach to investigating spatially variable upper plate deformation due to indentor tectonics in a thin-viscous sheet model, where the force of the slab is approximated as a boundary condition on the side of the model (England et al., 1985; England and Houseman, 1986; Finzel et al., 2011). Rather, with the 3D geographically referenced models that include the entire slab and its buoyancy effects, the role of the slab as it drives the upper plate deformation from underneath the upper plate is investigated (Jadamec et al., 2013; Eakin et al., 2014; Haynie and Jadamec, In Review 2016). Recent examples of the examination of the effect of a high-resolution geographically referenced slab have shown the slab geometry can have a first order control on upper plate deformation, including forearc sliver motion, laterally variable motion along intracontinental shear zones, and laterally variable basin and uplift formation, and demonstrate the importance of quantitatively investigating the effect of a detailed slab shape (Jadamec et al., 2013; Eakin et al., 2014; Haynie and Jadamec, In Review 2016). 


\subsection{A New Kind of Exploration in Scientific Data visualisation}

3D immersive virtual reality is an active area in Computational Science that is well suited for parsing the influx of digital information now available to the Earth Sciences (Erlebacher et al., 2001; Kreylos et al., 2006; Chen et al., 2008; Kellogg et al., 2008). 3D visualisation can have a direct impact on scientific discovery as hands-on 3D visualisation facilities allow researchers to gain new insights into the 3D modelling results and hence Earth processes (Kreylos et al., 2006; Kellogg et al., 2008; Jadamec and Billen, 2010). Moreover, scientific data visualisation is becoming increasingly critical in working with the design, input, and output from 3D geodynamic simulations (Figure 5).

With Gigabytes of data involved in the geodynamic model design, efficient mechanisms must be in place to inspect the 3D tectonic configurations (Erlebacher et al., 2001; Kreylos et al., 2006; Chen et al., 2008; Jadamec and Billen, 2012). Thus open source interactive 3D visualisation software becomes important to enable rapid inspection and interactive exploration of the 3D plate boundary geometry, thermal structure, as well as non-linear mantle flow fields (Kreylos et al., 2006; Kellogg et al., 2008). With interactive 3D data exploration, the quality and smoothness of the features mapped onto the model grid and results from complex 3D flow fields can be assessed and explored efficiently (Kreylos et al., 2006; Kellogg et al., 2008; Jadamec and Billen, 2010)

For high-resolution 3D geographically referenced models, the model construction phase and related 3D visualisation of this construction can lead to its own form of scientific discovery, particularly when different data sets are visualised in an immersive and interactive 3D environment. In global models, where the finest element size is $100 \mathrm{~km}, 50 \mathrm{~km}$, or even $25 \mathrm{~km}$, density anomalies could be mapped on the model grid assuming a global tomography model (van der Hilst et al., 1997; Romanow- 
icz, 2003; Li et al., 2008), and the detailed structure is less important. However, for high-resolution regional models, often multiple local seismic studies are required to complement the global constraints in order to characterize the slab and mantle structure at the scale of kilometers (Jadamec and Billen, 2010). Therefore, some $a$ priori synthesis of the disparate data types is required for mapping a given tectonic feature (slab, upper plate, plate interface) onto the grid (Figure 5) (Jadamec and Billen, 2012).

An interesting part of this process, is that the very act of having to map a complicate slab structure onto the mesh grid forces the modeler to grapple with questions such as how does a slab deform, as the complex slab shape in and of itself has implications for the strength and rheology (Jadamec and Billen, 2012). Therefore, in a sense, the modelers are now faced with similar conceptual realms of discovery as are field geologists (Figure 13a). The models can now handle the complexity, and it is up to the modelers to figure out how to adequately represent these structures and discover what they mean and imply for subduction dynamics (Figure 13b).

\subsection{Limitations of the modelling and Technology}

Caution must be used, however, such that the new technology is embraced with cognizance of limited data, numerical, and theoretical constraints. Mapping the features onto a high resolution mesh can be complicated and prone to errors or artifacts when the features are not aligned with respect to the mesh grid (Billen et al., 2008). This requires more sophisticated programming to construct the input (Jadamec and Billen, 2010). In addition, many assumptions arise in transferring the information to the grid. The use of multiple and disparate data sets to constrain the high resolution tectonic features also leads to challenges, as the resolution, error, and data 
density of the various observational constraints are typically different. Furthermore, a challenge with the high resolution models is a lack of data coverage, because the high-resolution mesh requires greater coverage in the observational constraints. This leads to need for some form of uncertainty quantification and also requires multiple phases of testing.

With the complicated geometries, it is even more necessary to run separate sets of models on simplified set-ups to optimize the solvers, particularly when using the nonlinear rheologies which can lead to viscosity variations of over 7 orders of magnitude over short spatial scales $(100 \mathrm{~km})$ (Moresi et al., 1996; Jadamec et al., 2012; Zhong et al., 2015). Moreover, it becomes increasingly important to understand the background physics and material properties upon which the models are based, such as what are the appropriate rheologies for the mantle especially when rock deformation experiments are extrapolated to strain rates over several orders of magnitude. It is not always clear how to represent a given set of geologic or geophysical observations in terms of physical parameters in the model, and this choice can vary for a given piece of software, or in a given numerical algorithm (Jadamec et al., 2012).

Another problem becomes scientific reproducibility. As various data sets are integrated in inconsistent ways and used in models, and as models are run with different versions of the numerical modelling software, it becomes a challenge to reproduce a given set of models and modelling results. As modelling codes are constantly being updated, future modelling efforts will need to archive the versions of codes used, as well 3D as model input.

\section{Conclusions}

Reflecting on the development of geodynamic modelling, the changes in technology have facilitated a major paradigm shift in our understanding of the nature of 
mantle flow in subduction zones. 3D models reveal the complex nature of slab-driven mantle flow, including trench parallel flow, toroidal flow around slab edges, mantle upwelling at lateral slab edges, small scale convection within the mantle wedge, and the effects of lateral gravitational instabilities above the mantle wedge.

Advances in high-performance computing allow geodynamicists to bring an unprecedented level of detail into numerical models, prompting a high-resolution 3D regional modelling approach and a new method for mapping the high resolution data onto a mesh grid. The coupling of the HPC with immersive three-dimensional data visualisation now allows the user to bring physical meaning to the hundreds of millions of numbers that numerically represent the model, enabling the numerical modeler to grasp the model components as would a laboratory modeler working with a tangible physical construct, and gives the visualisation a new role in scientific discovery. 


\section{Acknowledgements}

The author thanks Matthew Knepley, Karen Fischer, Dave Yuen, Maureen Long, Louis Moresi, Patricia Durance, Magali Billen, Frederik Simons, and Louise Kellogg for thoughtful discussions. The manuscript was greatly improved by insightful comments from Wouter Schellart, Vincent Strak, and two anonymous reviewers. Thank you to Louis Moresi and Shijie Zhong for the original Citcom* sources code, now hosted by the Computational Infrastructure for Geodynamics (http:// geodynamics.org/cig/software/citcomcu/). Thank you to Oliver Kreylos and and Burak Yikilmaz at the UC Davis KeckCAVES for the 3D visualisation infrastructure and software as well as discussions on data visualisation in Earth science. The work was supported by National Science Foundation Postdoc Fellowship EAR-1049545 and National Science Foundation Grant EAR-1352879 awarded to M. Jadamec. 
Abratis, M., Worner, G., 2001. Ridge collision, slab window formation, and the flux of Pacific asthenosphere into the Caribbean realm. Geology 29 (2), 127-130.

Abt, D. L., Fischer, K. M., Abers, G. A., Protti, M., Gonzalez, V., Strauch, W., 2010. Constraints from upper mantle anisotropy surrounding the Cocos slab from SK(K)S splitting. Journal of Geophysical Research 115 (B06316).

Alisic, L., Gurnis, M., Stadler, G., Burstedde, C., Ghattas, O., 2012. Multi-scale dynamics and rheology of mantle flow with plates. Journal of Geophysical Research: Solid Earth (1978-2012) 117 (B10).

Andrews, E. R., Billen, M. I., 2009. Rheologic controls on the dynamics of slab detachment. Tectonophysics 464, 60-69.

Artemieva, I., 2006. Global $1^{\circ} \times 1^{\circ}$ thermal model TC1 for the continental lithosphere: Implications for lithosphere secular evolution. Tectonophysics 416 (1-4), $245-277$.

Audoine, E., Savage, M. K., Gledhill, K., 2004. Anisotropic structure under a back arc spreading region, the Taupo Volcanic Zone, New Zealand. Journal of Geophysical Research: Solid Earth (1978-2012) 109 (B11).

Batchelor, G. K., 1967. An Introduction to Fluid Dynamics. Cambridge University Press, Cambridge, UK.

Baumann, T., Kaus, B. J., 2015. Geodynamic inversion to constrain the non-linear rheology of the lithosphere. Geophysical Journal International 202 (2), 1289-1316.

Becker, T. W., Kellogg, J. B., Ekstrom, G., O'Connell, R. J., 2003. Comparison of azimuthal seismic anisotropy from surface waves and finite strain from global mantle-circulation models. Geophysical Journal International 155, 696-714. 
Becker, T. W., O'Connell, R. J., 2001. Predicting plate velocities with mantle circulation models. Geochemistry, Geophysics and Geosystems 2 (12).

Behn, M. D., Hirth, G., Kelemen, P. B., 2007. Trench-parallel anisotropy produced by foundering of arc lower crust. Science 317, 108-111.

Bellahsen, N., Faccenna, C., Funiciello, F., 2005. Dynamics of subduction and plate motion in laboratory experiments: Insights into the "plate tectonics" behavior of the Earth. Journal of Geophysical Research 110 (B01401).

Bercovici, D., Ricard, Y., 2014. Plate tectonics, damage and inheritance. Nature 508 (7497), 513-516.

Billen, M., Jadamec, M. A., 2012. Origin of localized fast mantle flow velocity in numerical models of subduction. Geochemistry Geophysics Geosystems 13, Q01016.

Billen, M. I., Gurnis, M., 2001. A low viscosity wedge in subduction zones. Earth and Planetary Science Letters 193, 227-236.

Billen, M. I., Gurnis, M., 2003. Comparison of dynamic flow models for the central Aleutian and Tonga-Kermadec subduction zones. Geochemistry Geophysics Geosystems 4 (1035).

Billen, M. I., Gurnis, M., Simons, M., 2003. Multiscale dynamics of the TongaKermadec subduction zone. Geophysical Journal International 153, 359-388.

Billen, M. I., Hirth, G., 2005. Newtonian versus non-Newtonian upper mantle viscosity: Implications for subduction initiation. Geophysical Research Letters 32 (L19304). 
Billen, M. I., Hirth, G., 2007. Rheological controls on slab dynamics. Geochemistry Geophysics Geosystems 8 (Q08012).

Billen, M. I., Kreylos, O., Hamann, B., Jadamec, M. A., Kellogg, L. H., Staadt, O., Sumner, D. Y., 2008. A geoscience perspective on immersive 3D gridded data visualization. Computers \& Geosciences 34 (9), 1056-1072.

Bird, P., 2003. An updated digital model of plate boundaries. Geochemistry Geophysics Geosystems 4 (3), 1027.

Bower, D. J., Gurnis, M., Flament, N., 2015. Assimilating lithosphere and slab history in 4-d earth models. Physics of the Earth and Planetary Interiors 238, 8-22.

Bower, D. J., Gurnis, M., Seton, M., 2013. Lower mantle structure from paleogeographically constrained dynamic Earth models. Geochemistry, Geophysics, Geosystems 14 (1), 44-63.

Brown, J., Knepley, M. G., May, D. A., McInnes, L. C., Smith, B., 2012. Composable linear solvers for multiphysics. In: Parallel and Distributed Computing (ISPDC), 2012 11th International Symposium on. IEEE, pp. 55-62.

Brune, P. R., Knepley, M. G., Smith, B. F., Tu, X., 2015. Composing scalable nonlinear algebraic solvers. SIAM Review 57 (4), 535-565.

Burkett, E. R., Billen, M. I., 2009. Dynamics and implications of slab detachment due to ridge-trench collision. Journal of Geophysical Research: Solid Earth (19782012) 114 (B12).

Burkett, E. R., Billen, M. I., 2010. Three-dimensionality of slab detachment due to ridge-trench collision: Laterally simultaneous boudinage versus tear propagation. Geochemistry, Geophysics, Geosystems 11 (11). 
Burstedde, C., Ghattas, O., Stadler, G., Tu, T., Wilcox, L., 2009. Parallel scalable adjoint-based adaptive solution of variable-viscosity stokes flow problems. Computer Methods in Applied Mechanics and Engineering 198 (21-26), 1691-1700.

Buttles, J., Olson, P., 1998. A laboratory model of subduction zone anisotropy. Earth and Planetary Science Letters 164, 245-262.

Cagnioncle, A. M., Parmentier, E. M., Elkins-Tanton, L. T., 2007. Effect of solid flow above a subducting slab on water distribution and melting at convergent plate boundaries. Journal of Geophysical Research 112 (B09402).

Capitanio, F., Faccenda, M., 2012. Complex mantle flow around heterogeneous subducting oceanic plates. Earth and Planetary Science Letters 353, 29-37.

Capitanio, F., Faccenna, C., Zlotnik, S., Stegman, D., 2011. Subduction dynamics and the origin of andean orogeny and the bolivian orocline. Nature 480 (7375), $83-86$.

Capitanio, F. A., 2014. The dynamics of extrusion tectonics: Insights from numerical modeling. Tectonics 33 (12), 2361-2381.

Casey, J., Dewey, J., 1984. Initiation of subduction zones along transform and accreting plate boundaries, triple-junction evolution, and forearc spreading centresimplications for ophiolitic geology and obduction. Geological Society, London, Special Publications 13 (1), 269-290.

Castillo, P. R., 2012. Adakite petrogenesis. Lithos 134-135, 304-316.

Chen, S., Zhang, H., Yuen, D., Zhang, S., Zhang, J., Shi, Y., 2008. Volume rendering visualization of $3 \mathrm{D}$ spherical mantle convection with an unstructured mesh. Visual Geosciences 13 (1), 97-104. 
Christensen, D. H., Abers, G. A., 2010. Seismic anisotropy under central Alaska from SKS splitting observations. Journal of Geophysical Research 115 (B04315).

Cížková, H., van Hunen, J., van den Berg, A. P., 2007. Stress distribution within subducting slabs and their deformation in the transition zone. Physics of the Earth and Planetary Interiors 161, 202-214.

Conder, J., Wiens, D., 2007. Rapid mantle flow beneath the tonga volcanic arc. Earth and Planetary Science Letters 264 (1-2), 299-307.

Conrad, C., Behn, M., 2010. Constraints on lithosphere net rotation and asthenospheric viscosity from global mantle flow models and seismic anisotropy. Geochemistry Geophysics Geosystems 11 (5).

Conrad, C. P., Behn, M. D., Silver, P. G., 2007. Global mantle flow and the development of seismic anisotropy: Differences between the oceanic and continental upper mantle. Journal of Geophysical Research 112 (B07317).

Conrad, C. P., Lithgow-Bertelloni, C., 2002. How mantle slabs drive plate tectonics. Science 298, 207-209.

Crameri, F., Tackley, P., Meilick, I., Gerya, T., Kaus, B., 2012. A free plate surface and weak oceanic crust produce single-sided subduction on earth. Geophysical Research Letters 39 (3), L03306.

Crampin, S., Peacock, S., 2005. A review of shear-wave splitting in the compliant crack-critical anisotropic earth. Wave motion 41 (1), 59-77.

Currie, C. A., Hyndman, R. D., 2006. The thermal structure of subduction zone back arcs. Journal of Geophysical Research 111 (B08404). 
Defant, M. J., Drummond, M. S., 1990. Derivation of some modern arc magmas by melting of young subducted lithosphere. Nature 347, 662-665.

Di Leo, J., Walker, A., Li, Z.-H., Wookey, J., Ribe, N., Kendall, J.-M., Tommasi, A., 2014. Development of texture and seismic anisotropy during the onset of subduction. Geochemistry, Geophysics, Geosystems 15 (1), 192-212.

Dougherty, S. L., Clayton, R. W., 2014. Seismicity and structure in central Mexico: Evidence for a possible slab tear in the South Cocos plate. Journal of Geophysical Research: Solid Earth 119 (4), 3424-3447.

Drummond, M., Bordelon, M., De Boer, J., Defant, M., Bellon, H., Feigenson, M., 1995. Igneous petrogenesis and tectonic setting of plutonic and volcanic rocks of the Cordillera de Talamanca, Costa Rica-Panama, Central American arc. American Journal of Science 295 (7), 875.

Durance, P. M. J., Jadamec, M. A., Falloon, T. J., Nicholls, I. A., 2012. Magmagenesis within the Hunter Ridge Rift zone resolved from olivine-hosted melt inclusions and geochemical modelling, with insights from geodynamic models. Australian Journal of Earth Sciences 59 (6).

Eakin, C. M., Lithgow-Bertelloni, C., Dávila, F. M., 2014. Influence of Peruvian flatsubduction dynamics on the evolution of western Amazonia. Earth and Planetary Science Letters 404, 250-260.

Eberhart-Phillips, D., Christensen, D. H., Brocher, T. M., Hansen, R., Ruppert, N. A., Haeussler, P. J., Abers, G. A., 2006. Imaging the transition from Aleutian subduction to Yakutat collision in central Alaska, with local earthquakes and active source data. Journal of Geophysical Research 111 (B11303). 
Eberhart-Phillips, D., Haeussler, P. J., Freymueller, J. T., Frankel, A. D., Rubin, C. M., Craw, P., Ratchkovski, N. A., Anderson, G., Carver, G. A., Crone, A. J., Dawson, T. E., Fletcher, H., Hansen, R., Harp, E. L., Harris, R. A., Hill, D. P., Hreinsdottir, S., Jibson, R. W., Jones, L. M., Kayen, R., Keefer, D. K., Larsen, C. F., Moran, S. C., Personius, S. F., Plafker, G., Sherrod, B., Sieh, K., Sitar, N., Wallace, W. K., 2003. The 2002 Denali Fault Earthquake: A large magnitude, slip-partitioned event. Science 300, 1112-1118.

England, P., Houseman, G., 1986. Finite strain calculations of continental deformation 2. Comparison with the India-Asia collision zone. Journal of Geophysical Research 91 (B3), 3664-3676.

England, P., Houseman, G., Sonder, L., 1985. Length scales for continental deformation in convergent, divergent, and strike-slip environments: Analytical and approximate solutions for a thin viscous sheet model. J. of Geophys. Res. 90, 3551-3557.

Erlebacher, G., Yuen, D. A., Dubuffet, F., 2001. Current trends and demands in visualization in the geosciences. Visual Geosciences 6 (3), 1-59.

Faccenda, M., Burlini, L., Gerya, T. V., Mainprice, D., 2008. Fault-induced seismic anisotropy by hydration in subduction oceanic plates. Nature 455, 1097-1100.

Faccenda, M., Capitanio, F., 2012. Development of mantle seismic anisotropy during subduction-induced 3-D flow. Geophysical Research Letters 39 (11).

Faccenda, M., Capitanio, F., 2013. Seismic anisotropy around subduction zones: Insights from three-dimensional modeling of upper mantle deformation and SKS splitting calculations. Geochemistry, Geophysics, Geosystems 14 (1), 243-262. 
Faccenna, C., Becker, T. W., Lallemand, S., Lagabrielle, Y., Funiciello, F., Piromallo, C., 2010. Subduction-triggered magmatic pulses: A new class of plumes? Earth and Planetary Science Letters 299 (1), 54-68.

Finzel, E., Flesch, L., Ridgway, K., 2011. Kinematics of a diffuse North AmericaPacific-Bering plate boundary in Alaska and western Canada. Geology 39 (9), 835.

Fischer, K. M., Fouch, M. J., Wiens, D. A., Boettcher, M., 1998. Anisotropy and flow in pacific subduction zone back-arcs. Pure and Applied Geophysics 151, 463-475.

Fischer, K. M., Parmentier, E. M., Stine, A. R., Wolf, E., 2000. Modeling anisotropy and plate-driven flow in the Tonga subduction zone back arc. J. of Geophys. Res. 105 (B7), 16181-16191.

Fischer, T., Naumov, D., Sattler, S., Kolditz, O., Walther, M., 2015. Go2ogs 1.0: a versatile workflow to integrate complex geological information with fault data into numerical simulation models. Geoscientific Model Development 8 (11), 3681-3694.

Fouch, M. J., Fischer, K. M., 1996. Mantle anisotrophy beneath northwest Pacific subduction zones. Journal of Geophysical Research 101 (B7), 15987-16002.

Funiciello, F., Faccenna, C., Giardini, D., 2004. Role of lateral mantle flow in the evolution of subduction systems: insights from laboratory experiments. Geophysical Journal International 157, 1393-1406.

Gassmöller, R., Dannberg, J., Bredow, E., Steinberger, B., Torsvik, T. H., 2016. Major influence of plume-ridge interaction, lithosphere thickness variations, and global mantle flow on hotspot volcanism - The example of Tristan. Geochemistry, Geophysics, Geosystems 17 (4), 1454-1479. 
Gazel, E., Carr, M., Hoernle, K., Feigenson, M., Szymanski, D., Hauff, F., van den Bogaard, P., 2009. Galapagos-OIB signature in southern Central America: Mantle refertilization by arc-hot spot interaction. Geochemistry Geophysics Geosystems $10(2)$, Q02S11.

Gerya, T., 2011. Future directions in subduction modeling. Journal of Geodynamics $52(5), 344-378$.

Gerya, T. V., Yuen, D. A., Maresch, W. V., 2004. Thermomechanical modelling of slab detachment. Earth and Planetary Science Letters 226, 101-116.

Giuseppe, E. D., van Hunen, J., Funiciello, F., Faccenna, C., Giardini, D., 2008. Slab stiffness control of trench motion: Insights from numerical models. Geochemistry Geophysics Geosystems 9 (2), Q02014.

Govers, R., Wortel, M. J. R., 2005. Lithosphere tearing at step faults: Response to edges of subduction zones. Earth and Planetary Science Letters 236, 505-523.

Grand, S. P., 2002. Mantle shear-wave tomography and the fate of subducted slabs. Philosophical Transactions of the Royal Society of London A: Mathematical, Physical and Engineering Sciences 360 (1800), 2475-2491.

Greninger, M. L., Klemperer, S. L., Nokleberg, W. J., 1999. Geographic information systems (GIS) compilation of geophysical, geologic, and tectonic data for the circum-north Pacific. Open-File Report 99-422, United States Geological Survey.

Gropp, W., Kaushik, D., Keyes, D., Smith, B., 1999. Toward realistic performance bounds for implicit CFD codes. In: Proceedings of parallel CFD. Vol. 99. Citeseer, pp. 233-240. 
Gudmundsson, O., Sambridge, M., 1998. A regionalized upper mantle (RUM) seismic model. Journal of Geophysical Research 103 (B4), 7121-7136.

Guillaume, B., Moroni, M., Funiciello, F., Martinod, J., Faccenna, C., 2010. Mantle flow and dynamic topography associated with slab window opening: Insights from laboratory models. Tectonophysics 496 (1), 83-98.

Gurnis, M., Turner, M., Zahirovic, S., DiCaprio, L., Spasojevic, S., Müller, R., Boyden, J., Seton, M., Manea, V., Bower, D., 2012. Plate tectonic reconstructions with continuously closing plates. Computers \& Geosciences 38 (1), 35-42.

Gutscher, M. A., Spakman, W., Bijwaard, H., Engdahl, E. R., 2000. Geodynamics of flat subduction: Seismicity and tomographic constraints from the Andean margin. Tectonics 19 (5), 814-833.

Hager, B. H., 1991. Mantle viscosity: A comparison of models from postglacial rebound and from the geoid, plate driving forces, and advected heat flux. In: Sabodini, E. B. . R., Lambeck, K. (Eds.), NATO Advanced Research Workshop on Glacial Isostasy, Sea-Level, and Mantle Rheology. Vol. 334. Springer, New York, pp. $493-513$.

Hall, C. E., Fischer, K. M., Parmentier, E. M., Blackman, D. K., 2000. The influence of plate motions on three-dimensional back arc mantle flow and shear wave splitting. Journal of Geophysical Research 105 (B12), 28009-28033.

Hammond, J. O. S., Wookey, J., Kaneshima, S., Inoue, H., Yamashina, T., Harjadi, P., 2010. Systematic variation in anisotropy beneath the mantle wedge in the javasumatra subduction system from shear-wave splitting. Physics of the Earth and Planetary Interiors 178, 189-201. 
Hanna, J., Long, M., 2012. SKS splitting beneath Alaska: Regional variability and implications for subduction processes at a slab edge. Tectonophysics, 272-285.

Hartmann, J., Moosdorf, N., 2012. The new global lithological map database GLiM: A representation of rock properties at the Earth surface. Geochemistry, Geophysics, Geosystems 13 (12).

Hayes, G., Wald, D., Johnson, R., 2012. Slab1. 0: A three-dimensional model of global subduction zone geometries. Journal of Geophysical Research 117 (B1), B01302.

Haynie, K., Jadamec, M., In Review 2016. Tectonic drivers of the Wrangell block forearc sliver: Insights from 3D geodynamic models. Tectonics.

Heinecke, A., Breuer, A., Rettenberger, S., Bader, M., Gabriel, A.-A., Pelties, C., Bode, A., Barth, W., Liao, X.-K., Vaidyanathan, K., et al., 2014. Petascale high order dynamic rupture earthquake simulations on heterogeneous supercomputers. In: High Performance Computing, Networking, Storage and Analysis, SC14: International Conference for. IEEE, pp. 3-14.

Heyworth, Z., Knesel, K., Turner, S., Arculus, R., 2011. Pb-isotopic evidence for rapid trench-parallel mantle flow beneath Vanuatu. Journal of the Geological Society London 168, 265-271.

Hines, J., Billen, M., 2012. Sensitivity of the short-to intermediate-wavelength geoid to rheologic structure in subduction zones. Journal of Geophysical Research 117 (B5), B05410.

Hirth, G., Kohlstedt, D., 2003. Rheology of the upper mantle and the mantle wedge: A view from the experimentalists. In: Eiler, J. (Ed.), Inside the Subduction Fac- 
tory. Vol. 138 of Geophysical Monograph. American Geophysical Union, Washington, D. C., pp. 83-105.

Hoernle, K., Abt, D. L., Fischer, K. M., Nichols, H., Hauff, F., Abers, G. A., van den Bogaard, P., Heydolph, K., Alvarado, G., Protti, M., Strauch, W., 2008. Arcparallel flow in the mantle wedge beneath Costa Rica and Nicaragua. Nature 451, 1094-1098.

Holt, A., Becker, T., Buffett, B., 2015. Trench migration and overriding plate stress in dynamic subduction models. Geophysical Journal International 201 (1), 172-192.

Holtzman, B., Kohlstedt, D., Zimmerman, M., Heidelbach, F., Hiraga, T., Hustoft, J., 2003. Melt segregation and strain partitioning: implications for seismic anisotropy and mantle flow. Science 301 (5637), 1227-1230.

Honda, S., Saito, M., mantle wedge rolls upper mantle small scale convection models subduction viscosity numerical Japan 2003. Small-scale convection under the backarc occuring in the low viscosity wedge. Earth and Planet. Sci. Lett. 216, 703-715.

Houseman, G. A., Gubbins, D., 1997. Deformation of subducted oceanic lithosphere. Geophys. J. Int. 131, 535-551.

Hu, J., Liu, L., Hermosillo, A., Zhou, Q., 2016. Simulation of late Cenozoic South American flat-slab subduction using geodynamic models with data assimilation. Earth and Planetary Science Letters 438, 1-13.

Hyndman, R. D., Currie, C. A., Mazzotti, S. P., 2005. Subduction zone backarcs, mobile belts, and orogenic heat. GSA Today 15 (2). 
Jadamec, M., Durance, P., McLean, K., Billen, M., Moresi, L., 2011. Role of threedimensional mantle flow in magmatism at slab edges. Mineralogical Magazine 75 (3), 1097.

Jadamec, M. A., 2016. Slab driven mantle weakening and rapid mantle flow. In: G. Morra, D. A. Yuen, S. K. S. L., Stein, S. (Eds.), Subduction Dynamics. Vol. 211 of Geophysical Monograph Series. John Wiley \& Sons, pp. 135-156.

Jadamec, M. A., Billen, M. I., 2010. Reconciling surface plate motions and rapid three-dimensional flow around a slab edge. Nature 465 (7296), 338-341.

Jadamec, M. A., Billen, M. I., 2012. The role of rheology and slab shape on rapid mantle flow: Three-dimensional numerical models of the Alaska slab edge. Journal of Geophysical Research 117 (B02304).

Jadamec, M. A., Billen, M. I., Kreylos, O., 2012. Three-dimensional simulations of geometrically complex subduction with large viscosity variations. In: XSEDE '12 Proceedings of the 1st Conference of the Extreme Science and Engineering Discovery Environment: Bridging from the eXtreme to the campus and beyond. Association for Computing Machinery, pp. 1-8.

Jadamec, M. A., Billen, M. I., Roeske, S. M., 2013. Three-dimensional numerical models of flat slab subduction and the Denali fault driving deformation in southcentral Alaska. Earth and Planetary Science Letters 376, 29-42.

Jadamec, M. A., Fischer, K. M., 2014. Slab driven plate motions and threedimensional mantle flow pathways in the Central American subduction zone. In: Abstract T51B-4634, AGU Fall Meeting, San Francisco, CA, Dec 15-19. AGU. 
Jadamec, M. A., Wallace, W. K., 2014. Thrust-breakthrough of asymmetric anticlines: Observational constraints from surveys in the Brooks Range, Alaska. Journal of Structural Geology 62, 109-124.

Jarrard, R. D., 1986. Relations among subduction parameters. Reviews of Geophysics $24(2), 217-284$.

Johnston, S., Thorkelson, D., 1997. Cocos-Nazca slab window beneath Central America. Earth and Planetary Science Letters 146 (3-4), 465-474.

Jung, H., Karato, S.-I., 2001. Water-induced fabric transitions in olivine. Science 293, 1460-1463.

Kaminiski, E., Ribe, N. M., 2002. Timescales of the evolution of seismic anisotropy in mantle flow. Geology, Geochemistry and Geophysics 3 (1).

Kaminski, E., Ribe, N., Browaeys, J., 2004. D-rex, a program for calculation of seismic anisotropy due to crystal lattice preferred orientation in the convective upper mantle. Geophysical Journal International 158 (2), 744-752.

Karato, S., 2003. Mapping water content in the upper mantle. In: Eiler, J. (Ed.), Subduction Factory, AGU Monograph. Vol. 138. American Geophysical Union, Washington D. C., pp. 135-152.

Karato, S., Jung, H., Katayama, I., Skemer, P., 2008. Geodynamic significance of seismic anisotropy of the upper mantle: New insights from laboratory studies. Annual Reviews of Earth and Planetary Sciences 36 (59-95).

Katz, R., Spiegelman, M., Langmuir, C., 2003. A new parameterization of hydrous mantle melting. Geochemistry Geophysics Geosystems 4 (9), 1073. 
Katz, R. F., Takei, Y., 2013. Consequences of viscous anisotropy in a deforming, two-phase aggregate. part 2. numerical solutions of the full equations. Journal of Fluid Mechanics 734, 456-485.

Kaus, B. J. P., Podladchikov, Y. Y., 2006. Initiation of localized shear zones in viscoelastoplastic rocks. Journal of Geophysical Research 111 (B04412).

Kay, R. W., 1978. Aleutian magnesian andesites: melts from subducted Pacific ocean crust. Journal of Volcanology and Geothermal Research 4, 117-132.

Kay, R. W., Kay, S. M., 2002. Andean adakites: three ways to make them. Acta Petrologica Sinica 18 (3), 303-311.

Kelemen, P., Yogodzinski, G., Scholl, D., 2003. Along-strike variation in the Aleutian island arc: Genesis of high $\mathrm{Mg} \#$ andesite and implications for continental crust. In: Inside the Subduction Factory. Vol. 138. Geophysical Monograph, American Geophysical Union, pp. 223-276.

Kelley, K. A., Plank, T., Grove, T. L., Stolper, E. M., Newman, S., Hauri, E., 2006. Mantle melting as a function of water content beneath back-arc basins. Journal of Geophysical Research: Solid Earth (1978-2012) 111 (B9).

Kellogg, L. H., Bawden, G. W., Bernarndin, T., Billen, M., Cowgill, E., Hamann, B., Jadamec, M., Kreylos, O., Staadt, O., Sumner, D., 2008. Interactive visualization to advance earthquake simulation. Pure and Applied Geophysics 165, 621-633.

Keyes, D., Colella, P., Dunning Jr, T., Gropp, W., June 2003. A science-based case for large-scale simulation. Department of Energy, 51 pp.

Kincaid, C., Griffiths, R. W., 2003. Laboratory models of the thermal evolution of the mantle during rollback subduction. Nature 425, 58-62. 
King, S. D., 2001. Subduction zones: observations and geodynamic models. Physics of Earth and Planetary Interiors 127, 9-24.

King, S. D., Raefsky, A., Hager, B. H., 1990. ConMan: vectorizing a finite element code for incompressible two-dimensional convection in the Earth's mantle. Physics of Earth and Planetary Interiors 59, 195-207.

Kneller, E. A., van Keken, P. E., 2007. Trench-parallel flow and seismic anisotropy in the Mariana and Andean subduction systems. Nature 450 (7173), 1222-1226.

Kneller, E. A., van Keken, P. E., 2008. Effect of three-dimensional slab geometry on deformation in the mantle wedge: Implications for shear wave anisotropy. Geochemistry Geophysics Geosystems 9 (Q01003).

Kneller, E. A., van Keken, P. E., Katayama, I., Karato, S., 2007. Stress, strain and B-type olivine fabric in the fore-arc mantle: Sensitivity tests using high-resolution steady-state subductiono models. Journal of Geophysical Research 112 (B04406).

Kreemer, C., 2009. Absolute plate motions constrained by shear wave splitting orientations with implications for hot spot motions and mantle flow. Journal of Geophysical Research 114 (B10405).

Kreylos, O., Bawden, G. W., Bernardin, T., Billen, M. I., Cowgill, E. S., Gold, R. D., Hamann, B., Jadamec, M., Kellogg, L. H., Staadt, O. G., Sumner, D. Y., 2006. Enabling scientific workflows in virtual reality. In: Wong, K. H., Baciu, G., Bao, H. (Eds.), Proceedings of ACM SIGGRAPH International Conference on Virtual Reality Continuum and Its Applications 2006 (VRCIA 2006). ACM Press, New York, pp. 155-162. 
Kronbichler, M., Heister, T., Bangerth, W., 2012. High accuracy mantle convection simulation through modern numerical methods. Geophysical Journal International 191 (1), 12-29.

Lallemand, S., Heuret, A., Boutelier, D., 2005. On the relationships between slab dip, back-arc stress, upper plate absolute motion, and crustal nature in subduction zones. Geochemistry Geophysics Geosystems 6 (9), Q09006.

Laske, G., Masters, G., Ma, Z., Pasyanos, M., 2013. Update on crust1. 0-a 1-degree global model of earth's crust. In: EGU General Assembly Conference Abstracts. Vol. 15. p. 2658.

Leonard, T., Liu, L., 2016. The role of a mantle plume in the formation of Yellowstone volcanism. Geophysical Research Letters 43 (3), 1132-1139.

Lev, E., Hager, B. H., 2011. Anisotropic viscosity changes subduction zone thermal structure. Geochemistry, Geophysics, Geosystems 12 (4).

Li, C., van der Hilst, R. D., Engdahl, E. R., Burdick, S., 2008. A new global model for p wave speed variations in earth's mantle. Geochemistry Geophysics Geosystems $9(5)$.

Li, Z.-H., Di Leo, J. F., Ribe, N. M., 2014. Subduction-induced mantle flow, finite strain and seismic anisotropy: Numerical modeling. Journal of Geophysical Research: Solid Earth 119 (6), 5052-5076.

Lin, S.-C., 2014. Three-dimensional mantle circulations and lateral slab deformation in the southern chilean subduction zone. Journal of Geophysical Research: Solid Earth 119 (4), 3879-3896. 
Lin, S.-C., Kuo, B.-Y., 2016. Dynamics of the opposite-verging subduction zones in the taiwan region: Insights from numerical models. Journal of Geophysical Research: Solid Earth 121 (3), 2174-2192.

Lithgow-Bertelloni, C., Richards, M. A., 1998. The Dynamics of Cenozoic and Mesozoic plate motions. Reviews of Geophysics 36, 27-78.

Liu, L., Spasojević, S., Gurnis, M., 2008. Reconstructing Farallon plate subduction beneath North America back to the Late Cretaceous. Science 322 (5903), 934-938.

Liu, L., Stegman, D., 2012. Origin of Columbia River flood basalt controlled by propagating rupture of the Farallon slab. Nature 482 (7385), 386-389.

Liu, L., Stegman, D. R., 2011. Segmentation of the Farallon slab. Earth and Planetary Science Letters 311 (1), 1-10.

Long, M., Wirth, E. A., 2013. Mantle flow in subduction systems: The mantle wedge flow field and implications for wedge processes. Journal of Geophysical Research $118,1-24$.

Long, M. D., 2013. Constraints on subduction geodynamics from seismic anisotropy. Reviews of Geophysics.

Long, M. D., Becker, T. W., 2010. Mantle dynamics and seismic anisotropy. Earth and Planetary Science Letters 297 (3), 341-354.

Long, M. D., Silver, P. G., 2008. The subduction zone flow field from seismic anisotropy: A global view. Science 319, 315-318.

Long, M. D., Silver, P. G., 2009. Shear wave splitting and mantle anisotropy: Measurements, interpretations, and new directions. Surveys of Geophysics 30, 407-461. 
MacDougall, J., Fischer, K., Anderson, M., 2012. Seismic anisotropy above and below the subducting nazca lithosphere in southern south america. Journal of Geophysical Research: Solid Earth (1978-2012) 117 (B12).

MacDougall, J. G., Kincaid, C., Szwaja, S., Fischer, K. M., 2014. The impact of slab dip variations, gaps, and rollback on mantle wedge flow: insights from fluids experiments. Geophysical Journal International :ggu053.

Malatesta, C., Gerya, T., Crispini, L., Federico, L., Capponi, G., 2013. Oblique subduction modelling indicates along-trench tectonic transport of sediments. Nature communications 4 .

Manea, V., Gurnis, M., 2007. Subduction zone evolution and low viscosity wedges and channels. Earth and Planetary Science Letters 264 (1), 22-45.

Manea, V. C., Pérez-Gussinyé, M., Manea, M., 2012. Chilean flat slab subduction controlled by overriding plate thickness and trench rollback. Geology 40 (1), 35-38.

Mason, W. G., Moresi, L., Betts, P. G., Miller, M. S., 2010. Three-dimensional numerical models of the influence of a buoyant oceanic plateau on subduction zones. Tectonophysics 483, 71-79.

May, D., Moresi, L., 2008. Preconditioned iterative methods for stokes flow problems arising in computational geodynamics. Physics of the Earth and Planetary Interiors $171(1-4), 33-47$.

May, D. A., Sanan, P., Rupp, K., Knepley, M. G., Smith, B. F., 2016. Extreme-scale multigrid components within petsc. In: Proceedings of PASC 2016.

McKenzie, D., 1984. The generation and compaction of partially molten rock. Journal of Petrology 25 (3), 713-765. 
McKenzie, D. P., 1969. Speculations on the consequences and causes of plate motions. Geophys. J. Royal Astron. Soc. 18, 1-32.

McLean, K., 2010. Characterising three-dimensional mantle flow in the New Hebrides subduction system, southwest Pacific: Reconciling mantle flow with primitive arc lavas at the slab edge. Monash Univeristy, Honor's Thesis.

McLean, K., Jadamec, M., Durance, P., Moresi, L., 2011. Mantle flow at the New Hebrides slab edge, southwest Pacific: The juxtaposition of back-arc upwelling with the slab edge. International Union of Geodesy and Geophysics Conference, Melbourne, Australia.

Menant, A., Sternai, P., Jolivet, L., Guillou-Frottier, L., Gerya, T., 2016. 3d numerical modeling of mantle flow, crustal dynamics and magma genesis associated with slab roll-back and tearing: The eastern mediterranean case. Earth and Planetary Science Letters 442, 93-107.

Miller, M., Becker, T., 2012. Mantle flow deflected by interactions between subducted slabs and cratonic keels. Nature Geoscience 5 (10), 726-730.

Mitrovica, J., Forte, A., 2004. A new inference of mantle viscosity based upon joint inversion of convection and glacial isostatic adjustment data. Earth and Planetary Science Letters 225 (1), 177-189.

Moresi, L., Betts, P., Miller, M., Cayley, R., 2014. Dynamics of continental accretion. Nature 508 (7495), 245-248.

Moresi, L., Gurnis, M., 1996. Constraints on the lateral strength of slabs form threedimensional dynamic flow models. Earth and Planetary Science Letters 138, 15-28. 
Moresi, L., Quenette, S., Lemiale, V., Meriaux, C., Appelbe, B., Mulhaus, H. B., 2007. Computational approaches to studying non-linear dynamics of the crust and mantle. Physics of the Earth and Planetary Interiors 163, 69-82.

Moresi, L., Zhong, S., Gurnis, M., 1996. The accuracy of finite element solutions of Stoke's flow with strongly varying viscosity. Physics of the Earth and Planetary Interiors 97, 83-94.

Moresi, L. N., Solomatov, V. S., 1995. Numerical investigation of 2D convection with extremely large viscosity variations. Physics of Fluids 7 (9), 2154-2162.

Müller, R. D., Sdrolias, M., Gaina, C., Roest, W. R., 2008. Age, spreading rates, and spreading asymmetry of the world's ocean crust. Geochemistry Geophysics Geosystems 9 (4).

Nakajima, J., Hasegawa, A., 2007. Subduction of the Philippine Sea plate beneath southwestern Japan: Slab geometry and its relationship to arc magmatism. Journal of Geophysical Research 112 (B08306).

Nicolas, A., Christensen, N. I., 1987. Composition, Structure, and Dynamics of the Lithosphere-Asthenosphere System. American Geophysical Union, Washington, D.C., Ch. Formation of anisotropy in upper mantle peridotites - a review.

Paczkowski, K., Thissen, C. J., Long, M. D., Montési, L. G., 2014. Deflection of mantle flow beneath subducting slabs and the origin of subslab anisotropy. Geophysical Research Letters 41 (19), 6734-6742.

Page, R. A., Stephens, C. D., Lahr, J. C., 1989. Seismicity of the Wrangell and Aleutian Wadati-Benioff zones and the North American plate along the Trans- 
Alaska Crustal Transect, Chugach Mountains and Copper River Basin, southern Alaska. Journal of Geophysical Research 94 (B11), 16059-16082.

Patriat, M., Collot, J., Danyushevsky, L., Fabre, M., Meffre, S., Falloon, T., Rouillard, P., Pelletier, B., Roach, M., Fournier, M., 2015. Propagation of back-arc extension into the arc lithosphere in the southern New Hebrides volcanic arc. Geochemistry, Geophysics, Geosystems 16 (9), 3142-3159.

Peyton, V., Levin, V., Park, J., Brandon, M., Lees, J., Gordeev, E., Ozerov, A., 2001. Mantle flow at a slab edge: Seismic anisotropy in the Kamchatka region. Geophysical Research Letters 28 (2), 379-382.

Piromallo, C., Becker, T. W., Funiciello, F., Faccenna, C., 2006. Three-dimensional instantanteous mantle flow induced by subduction. Geophysical Research Letters 33 (L08304).

Pozgay, S. H., Wiens, D. A., Conder, J. A., Shiobara, H., Sugioka, H., 2007. Complex mantle flow in the mariana subduction system: Evidence from shear wave splitting. Geophysical Journal International 170, 371-386.

Preece, S. J., Hart, W. K., 2004. Geochemical variations in the $<5$ Ma Wrangell volcanic field, Alaska: implications for the magmatic and tectonic developement of a complex continental arc system. Tectonophysics 392, 165-191.

Ratchkovski, N. A., Hansen, R. A., 2002. New evidence for segmentation of the Alaska subduction zone. Bulletin of the Seismological Society of America 92 (5), $1754-1765$.

Regenauer-Lieb, K., Yuen, D. A., Branlund, J., 2001. The initiation of subduction: criticality by addition of water. Science $294,578-580$. 
Ribe, N., 2010. Bending mechanics and mode selection in free subduction: A thinsheet analysis. Geophysical Journal International 180 (2), 559-576.

Ricard, Y., Vigny, C., 1989. Mantle dynamics with induced plate tectonics. Journal of Geophysical Research: Solid Earth (1978-2012) 94 (B12), 17543-17559.

Rodríguez-González, J., Billen, M. I., Negredo, A. M., 2014. Non-steady-state subduction and trench-parallel flow induced by overriding plate structure. Earth and Planetary Science Letters 401, 227-235.

Romanowicz, B., 2003. Global mantle tomography: Progress status in the past 10 years. Annual Reviews of Earth and Planetary Science 31, 303-328.

Royden, L. H., Husson, L., 2006. Trench motion, slab geometry and viscous stresses in subduction systems. Geophysical Journal International 167 (881-905).

Rudi, J., Malossi, A. C. I., Isaac, T., Stadler, G., Gurnis, M., Staar, P. W., Ineichen, Y., Bekas, C., Curioni, A., Ghattas, O., 2015. An extreme-scale implicit solver for complex PDEs: highly heterogeneous flow in earth's mantle. SC15, doi:10.1145/2807591.2807675.

Russo, R. M., Silver, P. G., 1994. Trench-Parallel flow beneath the Nazca plate from seismic anisotropy. Science 263 (5150).

Savage, M. K., 1999. Seismic anisotropy and mantle deformation: What have we learned from shear wave splitting? Reviews of Geophysics 374 (12), 65-106.

Schellart, W., Moresi, L., 2013. A new driving mechanism for backarc extension and backarc shortening through slab sinking induced toroidal and poloidal mantle flow: Results from dynamic subduction models with an overriding plate. Journal of Geophysical Research: Solid Earth 118 (6), 3221-3248. 
Schellart, W., Stegman, D., Farrington, R., Moresi, L., 2011. Influence of lateral slab edge distance on plate velocity, trench velocity, and subduction partitioning. Journal of Geophysical Research: Solid Earth 116 (B10).

Schellart, W. P., 2004. Kinematics of subduction and subduction-induced flow in the upper mantle. Journal of Geophysical Research 109 (B07401).

Schellart, W. P., 2010. Mount Etna-Iblean volcanism caused by rollback-induced upper mantle upwelling around the Ionian slab edge: An alternative to the plume model. Geology 38 (8), 691-694.

Schellart, W. P., Freeman, J., Stegman, D. R., Moresi, L., May, D., 2007. Evolution and diversity of subduction zones controlled by slab width. Nature 446, 308-311.

Schellart, W. P., Stegman, D. R., Freeman, J., 2008. Global trench migration velocities and slab migration induced upper mantle volume fluxes: Constraints to find an earth reference frame based on minimizing viscous dissipation. Earth Science Reviews 88, 118-144.

Scire, A., Zandt, G., Beck, S., Long, M., Wagner, L., Minaya, E., Tavera, H., 2016. Imaging the transition from flat to normal subduction: variations in the structure of the Nazca slab and upper mantle under southern Peru and northwestern Bolivia. Geophysical Journal International 204 (1), 457-479.

Sdrolias, M., Müller, R. D., 2006. Controls on back-arc basin formation. Geochemistry Geophysics Geosystems 7 (4), Q04016.

Seton, M., Flament, N., Whittaker, J., Müller, R. D., Gurnis, M., Bower, D. J., 2015. Ridge subduction sparked reorganization of the Pacific plate-mantle system 60-50 million years ago. Geophysical Research Letters 42 (6), 1732-1740. 
Sharples, W., Jadamec, M. A., Moresi, L. N., Capitanio, F., 2014. Overriding plate controls on subduction evolution. Journal of Geophysical Research 119, 6684-6704.

Sharples, W., Moresi, L., Velic, M., Jadamec, M., May, D., 2016. Simulating faults and plate boundaries with a transversely isotropic plasticity model. Physics of the Earth and Planetary Interiors 252, $77-90$.

Silberling, N. J., Jones, D. L., Monger, J. W. H., Coney, P. J., Berg, H. C., Plafker, G., 1994. Plate 3: Lithotectonic terrane map of Alaska and adjacent parts of Canada. In: Plafker, G., Berg, H. (Eds.), The Geology of North America. Vol. G1, The Geology of Alaska. Geological Society of America, Boulder, Colo.

Skulski, T., Francis, D., Ludden, J., 1991. Arc-transform magmatism in the Wrangell volcanic belt. Geology 19, 11-14.

Sleep, N., Toksöz, M. N., 1971. Evolution of marginal basins. Nature 233, 548-550.

Smith, G. P., Wiens, D. A., Fischer, K. M., Dorman, L. M., Webb, S. C., Hilderbrand, J. A., 2001. A Complex Pattern of Mantle Flow in the Lau Backarc. Science 292, 713-716.

Song, T.-R. A., Kawakatsu, H., 2012. Subduction of oceanic asthenosphere: Evidence from sub-slab seismic anisotropy. Geophysical Research Letters 39.

Song, T.-R. A., Kawakatsu, H., 2013. Subduction of oceanic asthenosphere: A critical appraisal in central Alaska. Earth and Planetary Science Letters 367 (0), 82 - 94.

Spiegelman, M., 1993. Flow in deformable porous media. part 2 numerical analysisthe relationship between shock waves and solitary waves. Journal of Fluid Mechanics 247, 39-63. 
Stadler, G., Gurnis, M., Burstedde, C., Wilcox, L. C., Alisic, L., Ghattas, O., 2010. The dynamics of plate tectonics and mantle flow: From local to global scales. Science 329, 1033-1038.

Stegman, D. R., Freeman, J., Schellart, W. P., Moresi, L., May, D., 2006. Influence of trench width on subduction hinge retreat rates in 3D models of slab rollback. Geochemistry Geophysics Geosystems 7 (3), Q03012.

Strak, V., Schellart, W. P., 2014. Evolution of 3-D subduction-induced mantle flow around lateral slab edges in analogue models of free subduction analysed by stereoscopic particle image velocimetry technique. Earth and Planetary Science Letters 403, 368-379.

Strak, V., Schellart, W. P., 2016. Control of slab width on subduction-induced upper mantle flow and associated upwellings: Insights from analog models. Journal of Geophysical Research: Solid Earth.

Strohmaier, E., Dongarra, J., Simon, H., Meuer, M., Meuer, H., 2015. TOP500. URL http://www.top500.org/

Syracuse, E., van Keken, P., Abers, G., 2010. The global range of subduction zone thermal models. Physics of the Earth and Planetary Interiors 183 (1), 73-90.

Syracuse, E. M., Abers, G. A., 2006. Global compilation of variations in slab depth beneath arc volcanoes and implications. Geochemistry Geophysics Geosystems 7 (5), Q05017.

Syracuse, E. M., Maceira, M., Prieto, G. A., Zhang, H., Ammon, C. J., 2016. Multiple plates subducting beneath Colombia, as illuminated by seismicity and velocity 
from the joint inversion of seismic and gravity data. Earth and Planetary Science Letters 444, 139-149.

Tackley, P., 1996. Effects of strongly variable viscosity on three-dimensional compressible convection in planetary mantles. Journal of Geophysical Research 101 (B2), 3311-3332.

Taramón, J. M., Rodríguez-González, J., Negredo, A. M., Billen, M. I., 2015. Influence of cratonic lithosphere on the formation and evolution of flat slabs: Insights from 3-d time-dependent modeling. Geochemistry, Geophysics, Geosystems 16 (9), 2933-2948.

Tommasi, A., Tikoff, B., Vauchez, A., 1999. Upper mantle tectonics: threedimensional deformation, olivine crystallographic fabrics and seismic properties. Earth and Planetary Science Letters 168, 173-186.

Tovish, A., Schubert, G., Luyendyk, B. P., 1978. Mantle flow pressure and the angle of subduction: Non-Newtonian corner flows. Journal of Geophysical Research 83, $5892-5898$.

Trop, J. M., Hart, W. K., Snyder, D., Idleman, B., 2012. Miocene basin development and volcanism along a strike-slip to flat-slab subduction transition: Stratigraphy, geochemistry, and geochronology of the central wrangell volcanic belt, yakutatnorth america collision zone. Geosphere, GES00762-1.

van der Hilst, R. D., Widiyantoro, S., Engdahl, E. R., 1997. Evidence for deep mantle circulation from global tomography. Nature $386,578-584$.

van Hunen, J., Allen, M. B., 2011. Continental collision and slab break-off: a com- 
parison of 3-d numerical models with observations. Earth and Planetary Science Letters 302 (1), 27-37.

van Keken, P. E., Currie, C., King, S. D., Behn, M. D., Cagnioncle, A., He, J., Katz, R. F., Lin, S.-C., Parmentier, E. M., Spiegelman, M., et al., 2008. A community benchmark for subduction zone modeling. Physics of the Earth and Planetary Interiors $171(1), 187-197$.

Van Keken, P. E., Kiefer, B., Peacock, S. M., 2002. High-resolution models of subduction zones: Implications for mineral dehydration reactions and the transport of water into the deep mantle. Geochemistry, Geophysics, Geosystems 3 (10).

Van Staal, C., Dewey, J., Mac Niocaill, C., McKerrow, W., 1998. The CambrianSilurian tectonic evolution of the northern Appalachians and British Caledonides: history of a complex, west and southwest Pacific-type segment of Iapetus. Geological Society, London, Special Publications 143 (1), 197-242.

Wada, I., He, J., Hasegawa, A., Nakajima, J., 2015. Mantle wedge flow pattern and thermal structure in northeast Japan: effects of oblique subduction and 3-D slab geometry. Earth and Planetary Science Letters 426, 76-88.

Wada, I., Wang, K., He, J., Hyndman, R. D., 2008. Weakening of the subduction interface and its effects on surface heat flow, slab dehydration, and mantle wedge serpentinization. Journal of Geophysical Research 113 (B04402).

Wade, J., Plank, T., Hauri, E., Kelley, K., Roggensack, K., Zimmer, M., 2008. Prediction of magmatic water contents via measurement of $\mathrm{H}_{2} \mathrm{O}$ in clinopyroxene phenocrysts. Geology 36 (10), 799-802.

White, F. M., 2003. Fluid mechanics. 5th. Boston: McGraw-Hill Book Company. 
Williams, S. E., Müller, R. D., Landgrebe, T. C., Whittaker, J. M., 2012. An open-source software environment for visualizing and refining plate tectonic reconstructions using high-resolution geological and geophysical data sets. GSA Today $22(4 / 5), 4-9$.

Wilson, C. R., Spiegelman, M., van Keken, P. E., Hacker, B. R., 2014. Fluid flow in subduction zones: The role of solid rheology and compaction pressure. Earth and Planetary Science Letters 401, 261-274.

Wirth, E. A., Korenaga, J., 2012. Small-scale convection in the subduction zone mantle wedge. Earth and Planetary Science Letters 357, 111-118.

Wortel, R., Govers, R., Spakman, W., 2009. Continental collision and the stepwise evolution of convergent plate boundaries: From structure to dynamics. In: Subduction Zone Geodynamics. Springer, pp. 47-59.

Yang, X., Fischer, K. M., Abers, G. A., 1995. Seismic anisotropy beneath the Shumagin Islands segment of the Aleutian-Alaska subduction zone. Journal of Geophysical Research: Solid Earth (1978-2012) 100 (B9), 18165-18177.

Yogodzinski, G. M., Kay, R. W., Volynets, O. N., Koloskov, A. V., Kay, S. M., 1995. Magnesian andesite in the Western Aleutian Komandorsky region - implications for slab melting and processes in the mantle wedge. J. of Geophys. Res. 107, 505-519.

Zandt, G., Humphreys, E., 2008. Toroidal mantle flow through the western U.S. slab window. Geology 36 (4), 295-298.

Zhao, D., Yanada, T., Hasegawa, A., Umino, N., Wei, W., 2012. Imaging the subducting slabs and mantle upwelling under the Japan Islands. Geophysical Journal International 190 (2), 816-828. 
Zhong, S., 2006. Constraints on thermochemical convection of the mantle from plume heat flux, plume excess temperature, and upper mantle temperature. Journal of Geophysical Research 111 (B04409).

Zhong, S., Gurnis, M., 1996. Interaction of weak faults and non-Newtonian rheology produces plate tectonics in a 3D model of mantle flow. Nature 383, 245-247.

Zhong, S., Yuen, D., Moresi, L., 2007. Numerical methods for mantle convection. Treatise on Geophysics 7, 227-252.

Zhong, S., Yuen, D. A., Moresi, L. N., Knepley, M. G., 2015. Numerical methods for mantle convection. In: Schubert, G. (Ed.), Treatise on Geophysics, second edition Edition. Vol. 7. Elsevier.

Zhong, S., Zuber, M. T., Moresi, L., Gurnis, M., 2000. Role of temperaturedependent viscosity and surface plates in spherical shell models of mantle convection. Journal of Geophysical Research 105 (B5), 11063-11082. 


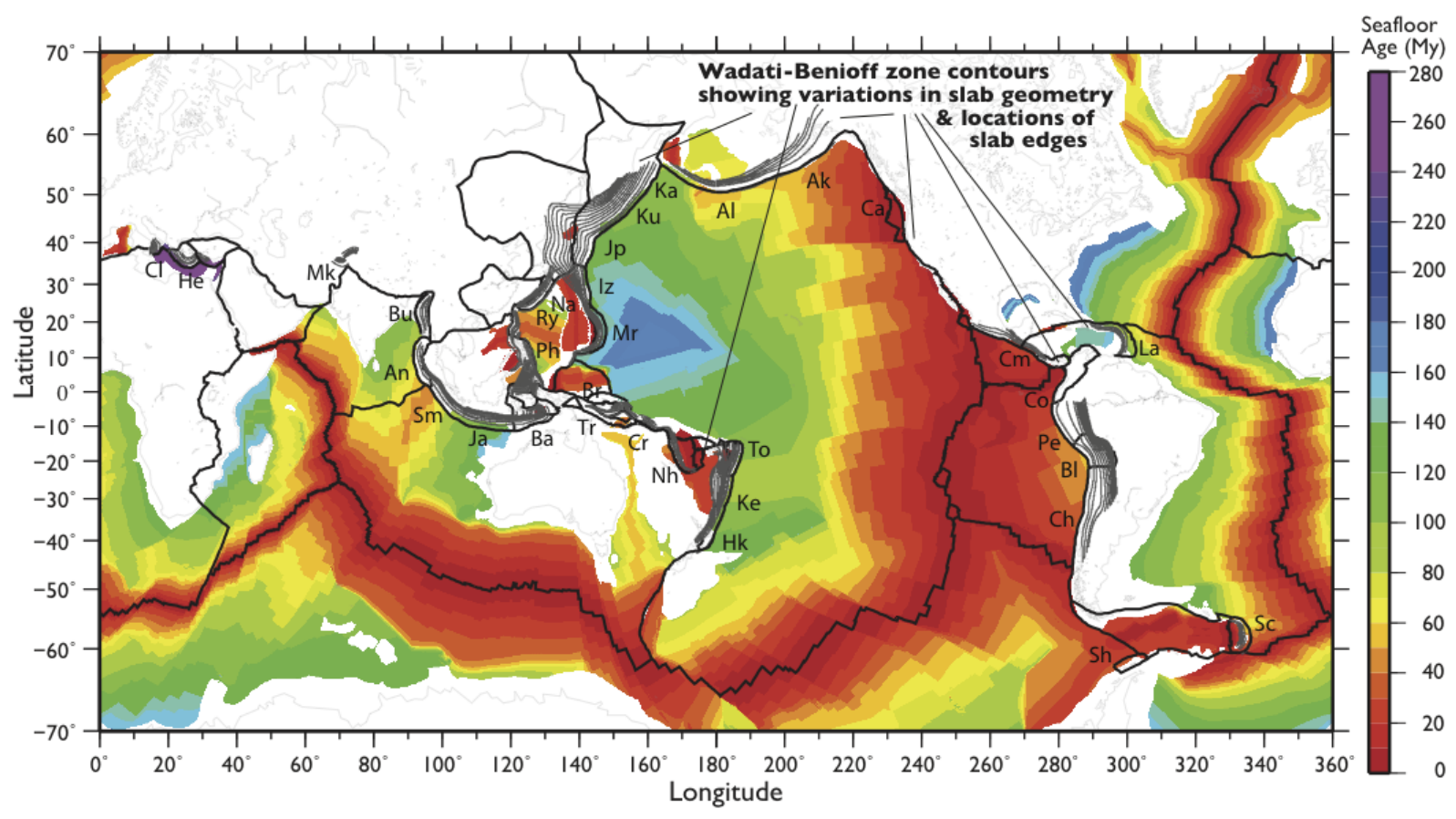

Figure 1: Global tectonic map of plate boundaries (black lines - Bird (2003)), slab surface contours in $50 \mathrm{~km}$ intervals (gray lines - Gudmundsson and Sambridge (1998)), and ages of the oceanic plates (color - Müller et al. (2008)). Subduction zones: Ak - Alaska, Al - Aleutian, An - Andaman, Ba Banda, Bl - Bolivia, Br - New Britain, Bu - Burma, Ca - Cascadia, Ch - Chile, Cl - Calabria, Cm - Central America, Co - Columbia, He - Hellenic, Hi - Hikarangi, Iz - Izu, Ja - Java, Jp - Japan, Ka - Kamchatka, Ke - Kermadec, Ku - Kurile, La - Lesser Antilles, Mk - Makran, Mr - Marianas, Na - Nankai, Nb - , Nh - New Hebrides, Pe - Peru, Ph - Philippine, Ry - Ryuku, Sc - Scotia, Sh South Shetland, Sm - Sumatra, To - Tonga, Tr - Trobriand. For additional plate boundary labels see Schellart et al. (2008). 


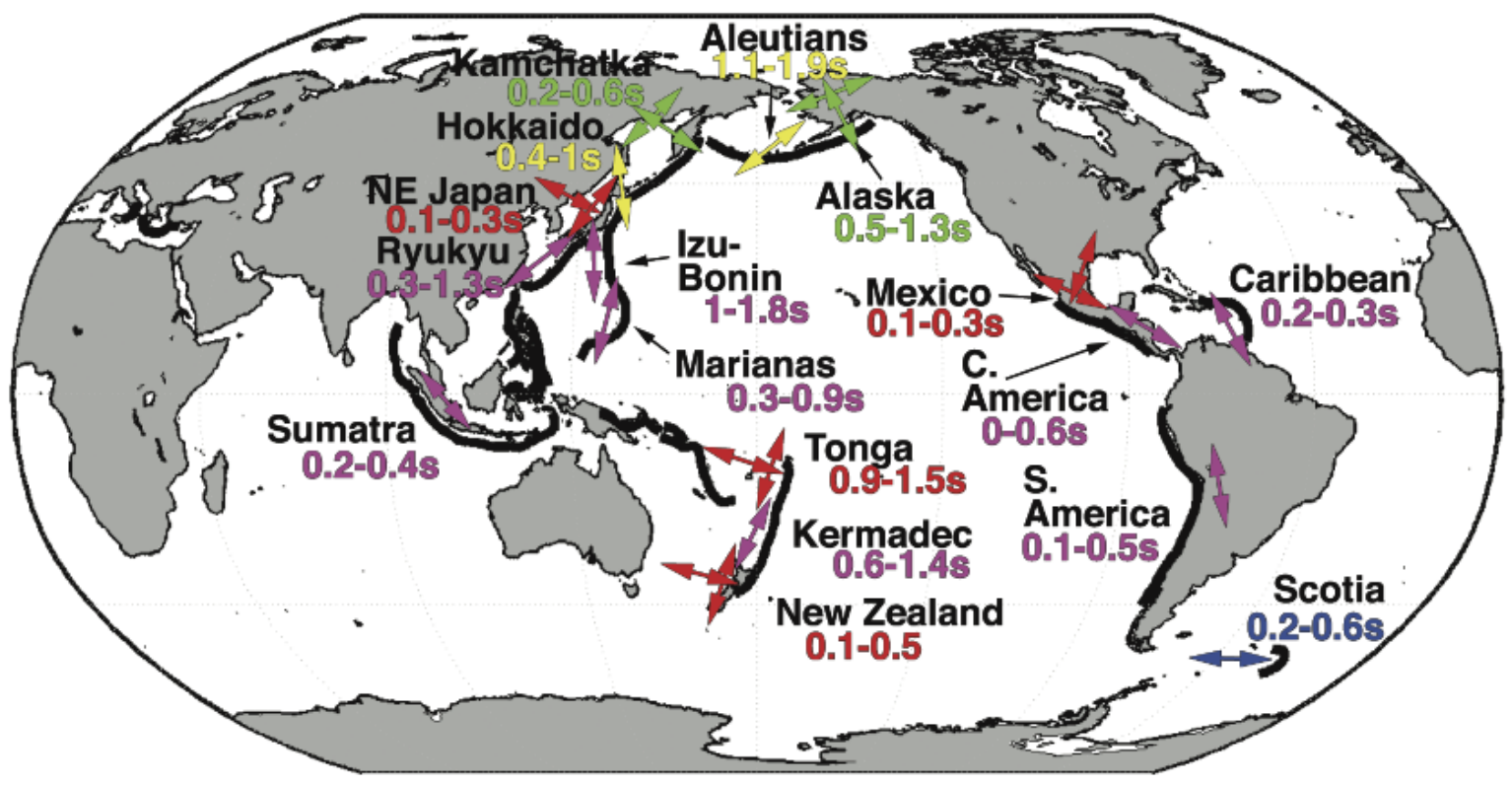

Figure 2: Global synthesis of shear wave splitting in the mantle wedge. Arrows represent azimuth of the average seismic fast directions and are color-coded by the pattern of the azimuths of the seismic fast axes with respect to the trench. The patterns show a range from trench perpendicular to trench parallel fast directions. Numbers give range in delay times. Figure from Long and Wirth (2013). 


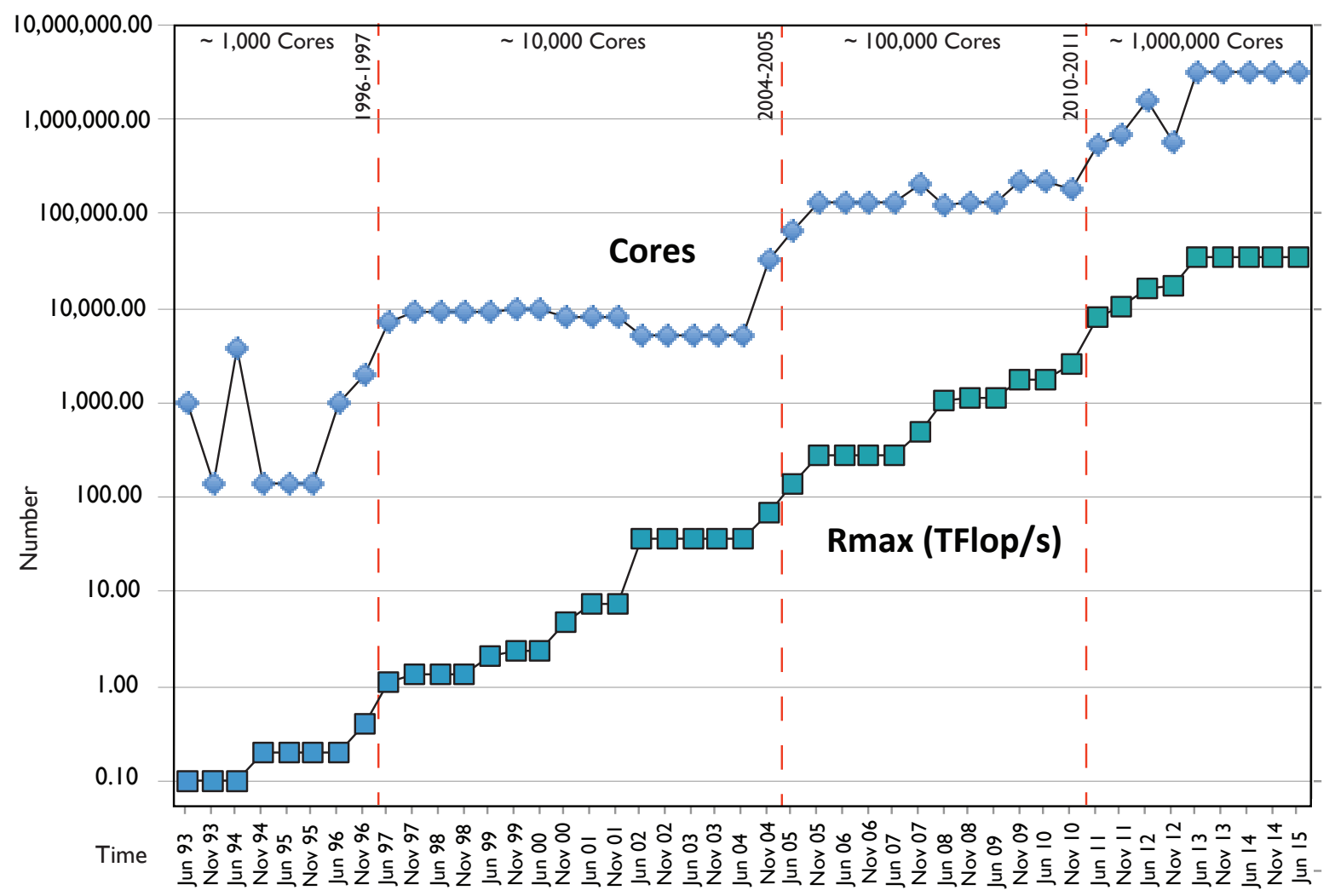

Figure 3: Total cores and Rmax value for supercomputers worldwide ranked Number 1, from 1993-2015, according to TOP500 list ranked by performance on LINPACK Benchmark (Strohmaier et al. (2015), http://www.top500.org). Both the number of compute cores and Rmax (TFlops/s) are plotted, wherein the Rmax is a measure of the peak number of floating point operations (Flops) per second, in Tera-Flops. 


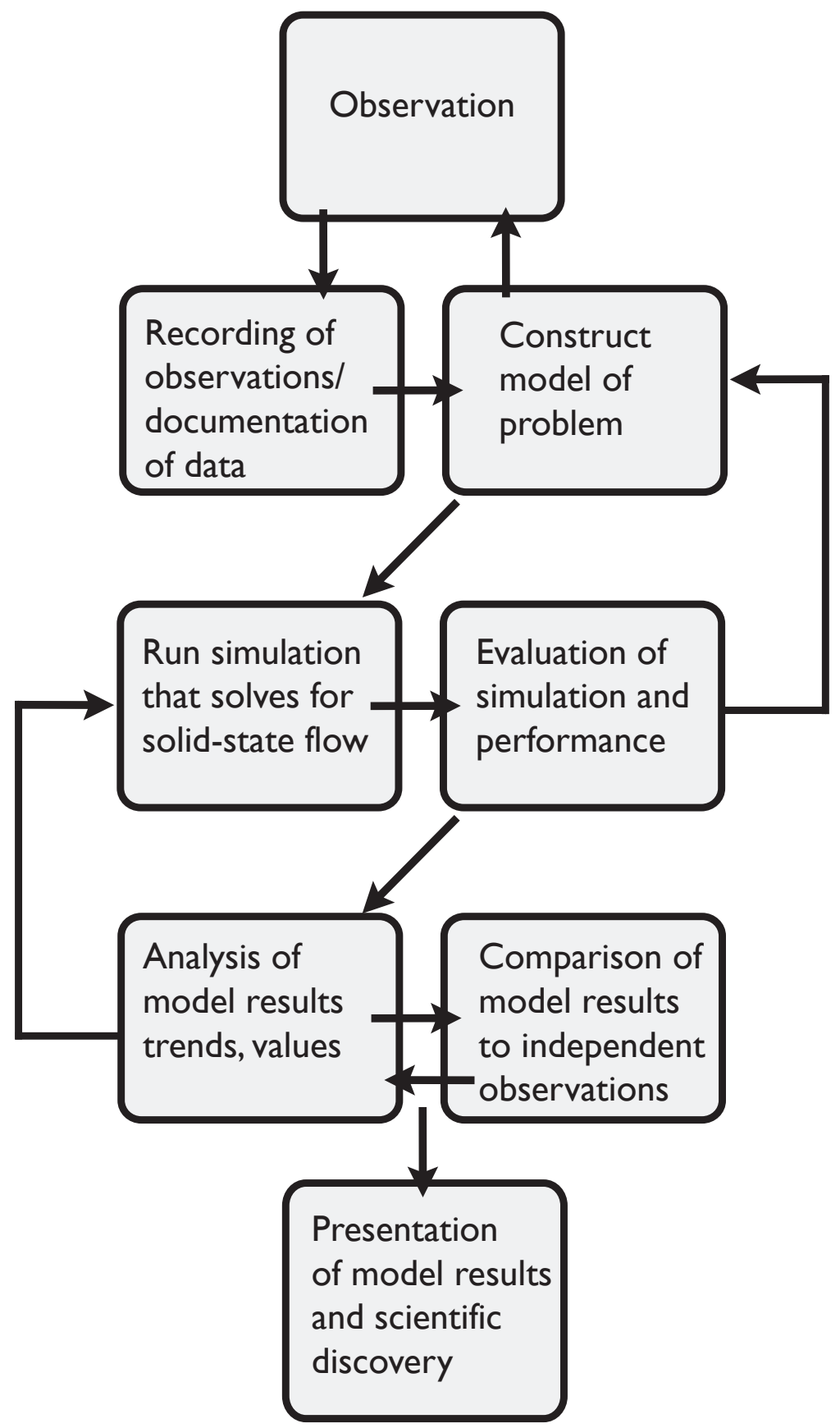

Figure 4: Schematic of steps in geodynamic modelling workflow. For 3D regional models incorporating extensive observationally based model design, the model design step can take as long as the model run step. In addition, the model performance and evaluation steps are typically longer due to the more complicated geometries and rheologies in regionally based models. 
a)

\begin{tabular}{|l|l|}
\hline I. Data Collection and Pre-processing \\
\hline $\begin{array}{l}\text { Data Collection: } \\
\text { Wadati-Benioff Zone Seismicity } \\
\text { Slab Contours, Tomography } \\
\text { Seafloor Ages }\end{array} \begin{array}{l}\text { Pre-Processing: } \\
\text { Build slab surface geometry, } \\
\text { extract, filter, consolidate } \\
\text { observational data, prep files. } \\
\text { Pre-processing with GMT, } \\
\text { Mepth to base of lithosphere } \\
\text { MATLAB, Python, shell scripts }\end{array}$ \\
\hline
\end{tabular}

b)

\section{Construct 3D Tectonic Configuration}

\begin{tabular}{|l|l|}
\hline $\begin{array}{l}\text { Input to Model } \\
\text { Builder Code: }\end{array}$ & $\begin{array}{l}\text { Output mapped onto 2D or } \\
\text { 3D mesh from Builder Code: }\end{array}$ \\
Model bounds & Multi-resolution model mesh \\
Plate interface(s) & Inter-plate shear zone \\
Fault/Shear zone surface(s) & Intra-plate shear zone \\
Slab surface(s) & Slab thermal field \\
Seafloor age grid & Slab, upper mantle thermal field \\
Upper plate ages & Upper plate, mantle thermal field \\
\hline
\end{tabular}

c)

III. Solve Conservation Equations for Flow

Input to Viscous
Simulation Code:
Mesh vectors
Inter-plates shear zone
Thermal Structure mapped
onto model mesh
(includes slab, upper plate
and mantle)

Output from Viscous Simulation Code: Velocity, Pressure Stress, Strain-rate Invariant Temperature

Composite Viscosity Composition

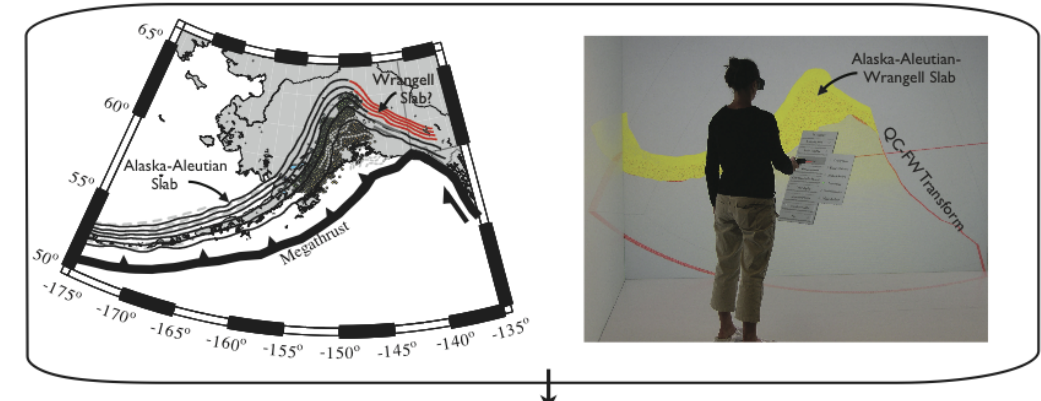

$\downarrow$
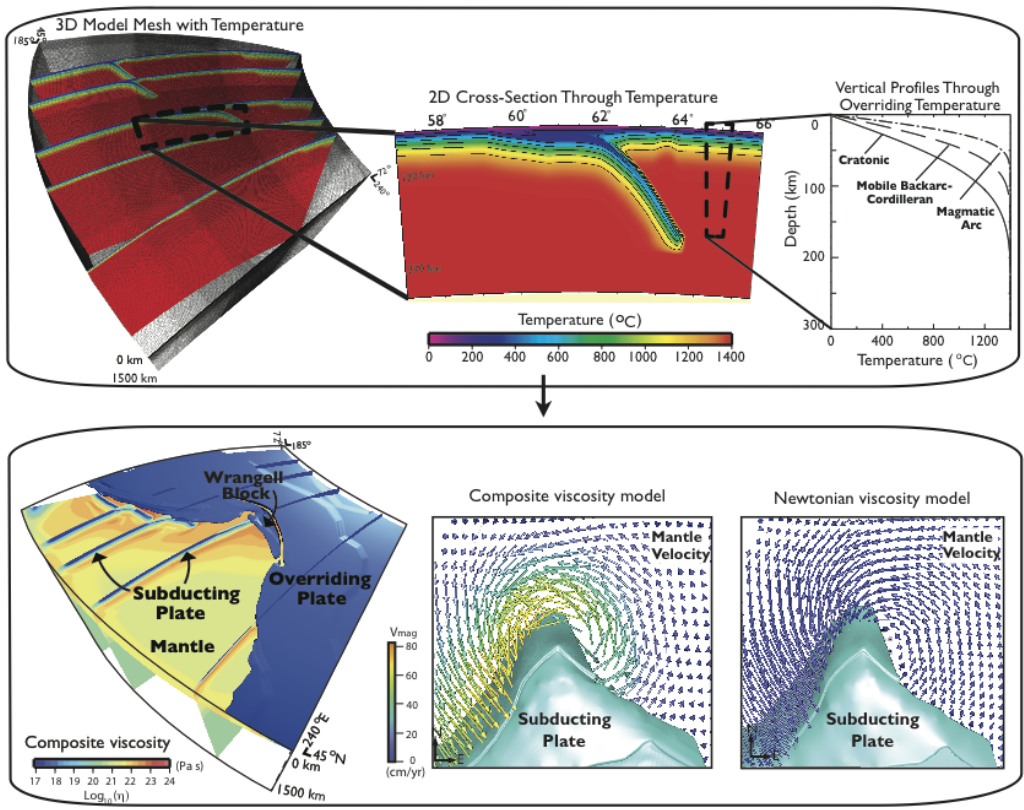

Figure 5: Workflow for high resolution regional 3D numeric models. (a) Data collection and preprocessing. (b) Example of three-dimensional variable-resolution model mesh and three-dimensional thermal structure in the overriding plate, subducting plate, and mantle generated by SubductionGenerator. (c) The thermal structure is used to calculate the density anomalies that drive the viscous flow in CitcomCU. Flow field shown for subset of model domain. 3D images modified from Kellogg et al. (2008); Jadamec and Billen (2010, 2012); Jadamec et al. (2013). 
a)

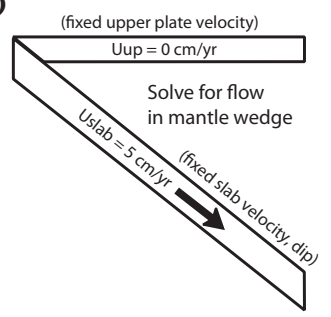

b)

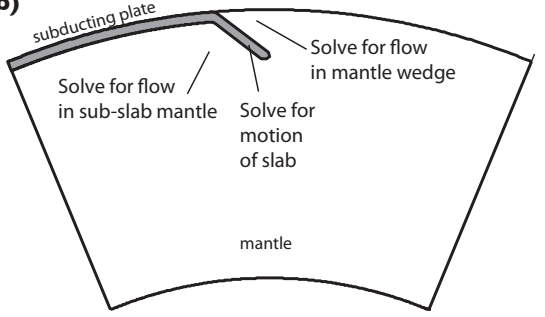

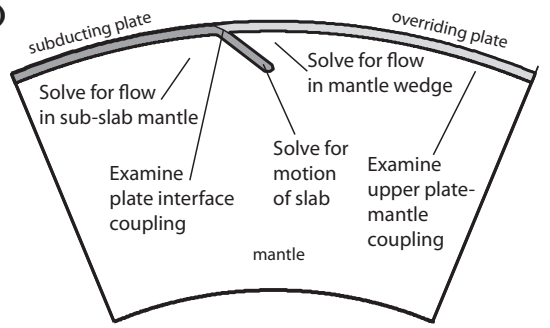

Figure 6: Schematic 2D subduction model set-up. (a) 2D corner flow model that solves for flow in mantle wedge, with a plate velocities applied as a boundary condition. (b) 2D free subduction model that solves for subslab flow, mantle wedge flow, and slab deformation. (c) 2D subduction model with overriding plate that solves for upper plate motion as well as subslab flow, mantle wedge flow, and slab deformation. 
a)

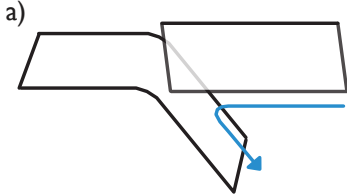

d)

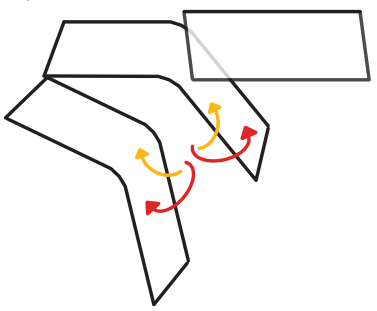

b)

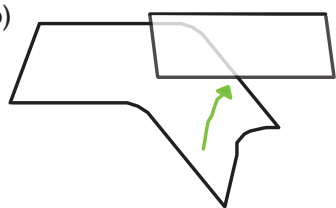

e)

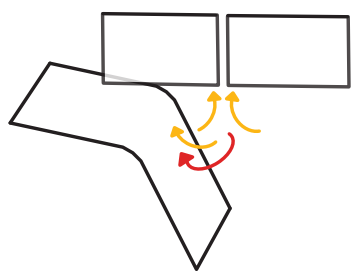

c)
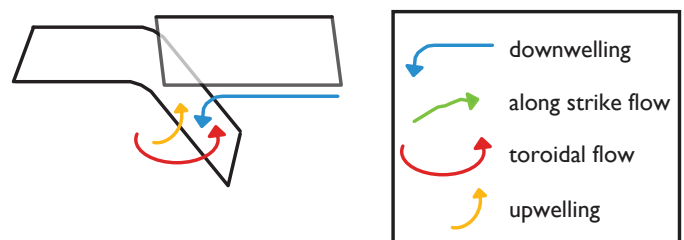

f)

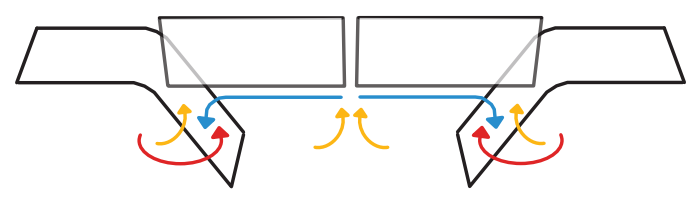

Figure 7: slab-driven mantle flow cartoons. (a) 2D corner flow in the mantle wedge with the downwelling parallel to the slab surface. (b) Along strike flow in the mantle wedge due to along strike slab dip variability and pressure gradients. (c) Downwelling in the mantle wedge due to steeping and/or slab rollback of a free slab such that the flow is at an angle to the slab surface, toroidal flow around the slab edge, and associated upwelling at lateral slab edge. (d) Subduction zone with slab window/tear and two opposing cells of toroidal flow and slab edge upwelling. (e) Slab edge intersection with back-arc spreading center, showing both toroidal flow and slab edge upwelling as well as upwelling associated with back arc spreading. (f) Opposing subduction zones with slab steepening and back arc spreading. 

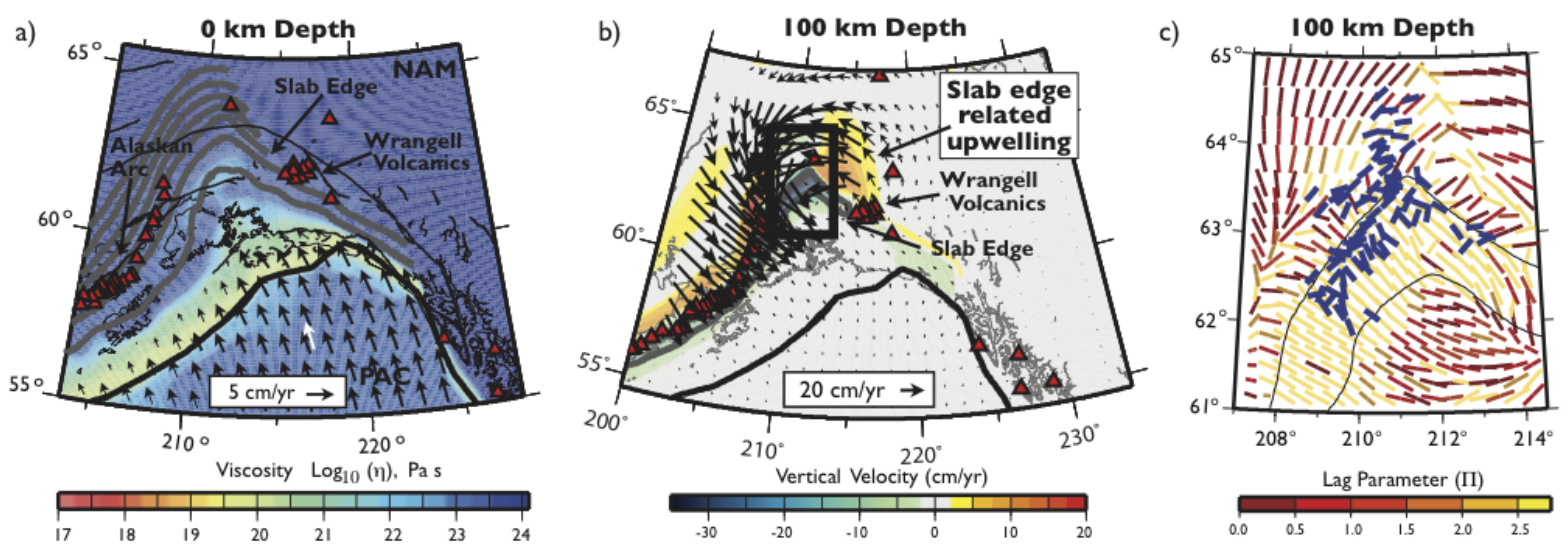

Figure 8: Predicted flow velocities in high-resolution 3D instantaneous model of the North American-Pacific plate system in Alaska, with subset of model domain shown. Predicted Pacific plate motion (black arrows)(a) is non-parallel to counterclockwise toroidal flow in mantle at 100 $\mathrm{km}$ depth (b). (c) Comparison of calculated infinite strain axes (colored bars) from flow field in Jadamec and Billen (2010) (b) to the fast axes of seismic anisotropy from Christensen and Abers (2010) (blue bars). Modified from Jadamec and Billen (2010). 

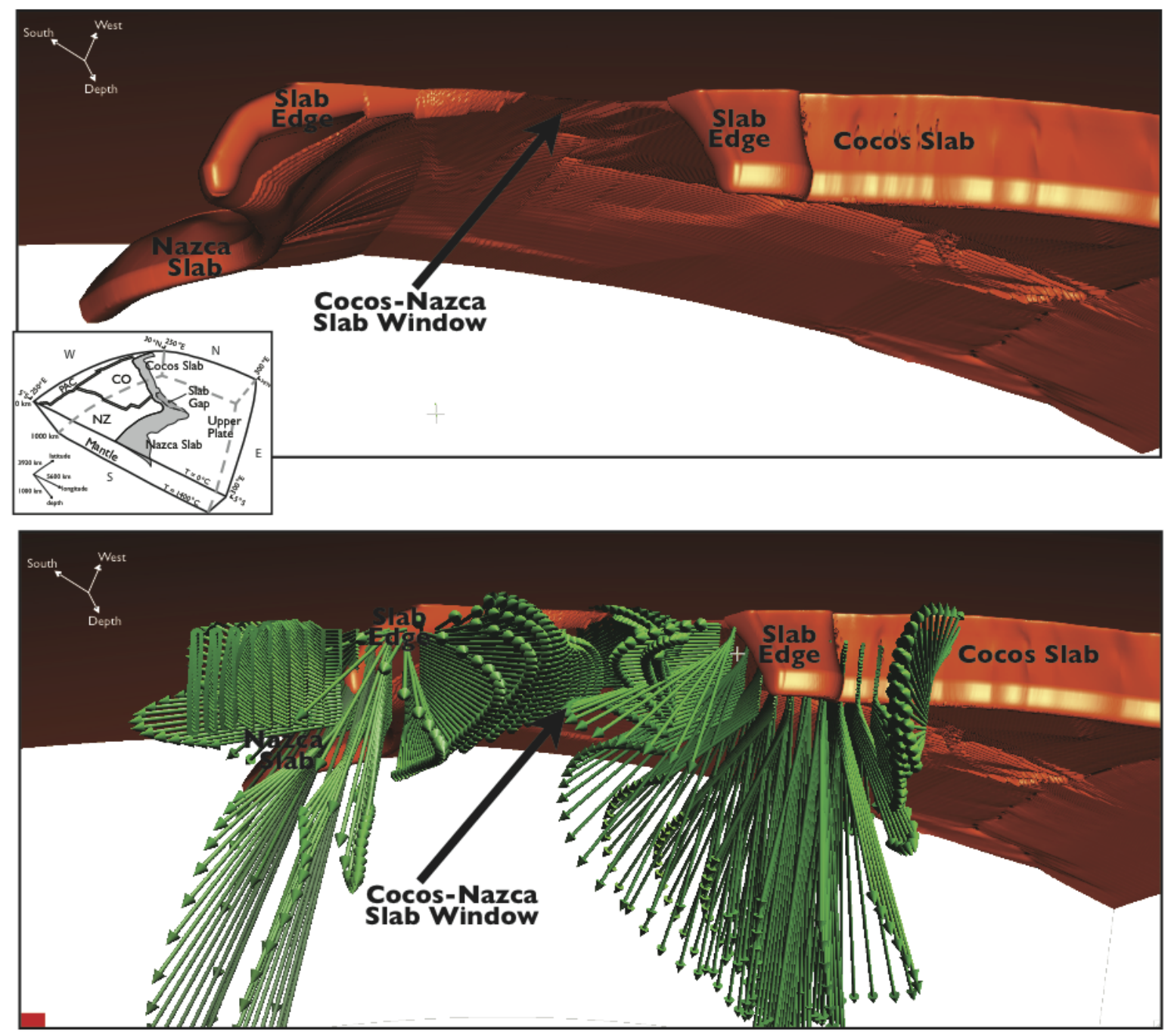

Figure 9: Example of three-dimensional mantle flow through Cocos-Nazca slab window from a highresolution regional slab model of the Caribbean plate region, showing counterclockwise toroidal flow around the southern Cocos slab edge and clockwise toroidal flow around the northern Nazca slab edge. The 3D thermal structure was constructed with SubductionGenerator (Jadamec et al., 2012; Jadamec and Billen, 2012). Model domain given in the inset was discretized into 897 x 865 x 113 elements in the longitude, latitude, and radial directions, respectively, and mesh resolution ranges from $2.35 \mathrm{~km}$ to $25 \mathrm{~km}$, with the finest resolution centered on the slab gap (Jadamec and Fischer, 2014). Model was run on 384 processors for 24 hours ( 9000 core hours) using the open source mantle convection code CitcomCU (Zhong, 2006) with free-slip boundary conditions, and used the composite viscosity formulation based on the experimentally derived flow law for olivine (Hirth and Kohlstedt, 2003) implemented in Jadamec and Billen (2010). Dimensionalization and flow law parameters are the same as those used in Jadamec and Billen (2010). The examination of the length-scales of the flow is still actively being studied. 
a)

Zone of overriding plate subducting plate coupling

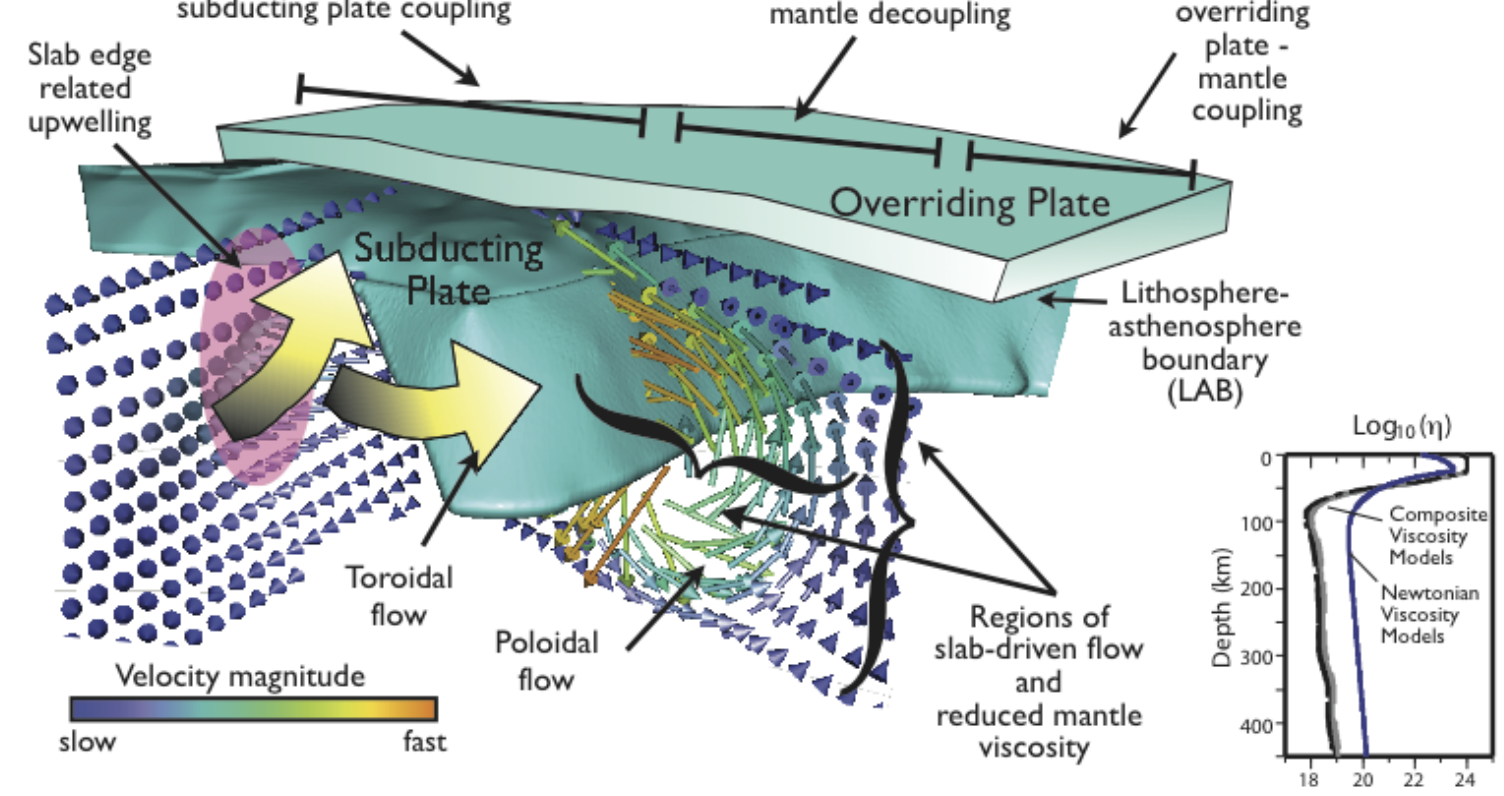

Far-field overriding

b)

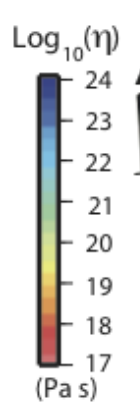

c)

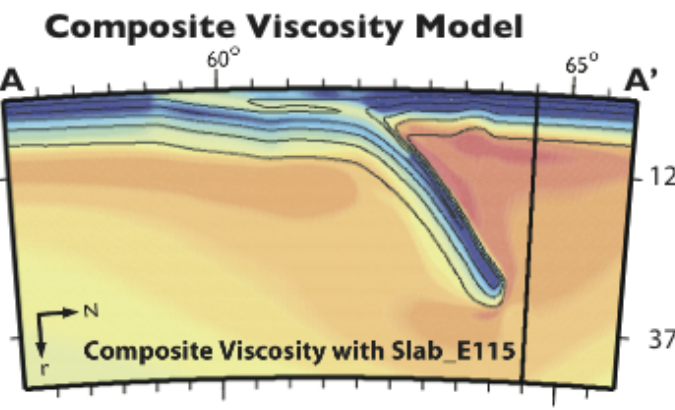

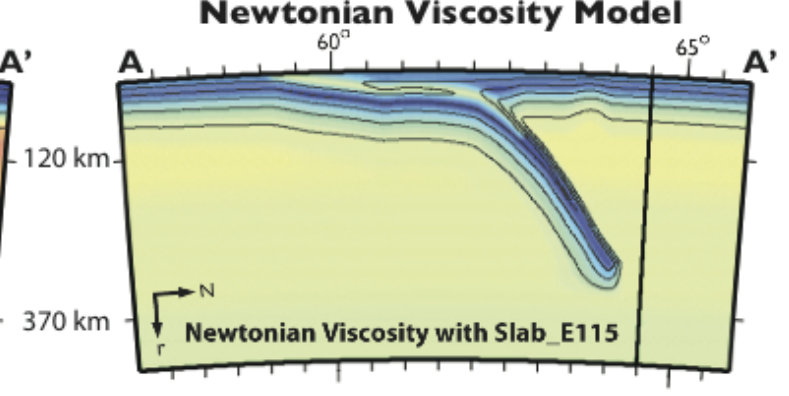

Figure 10: Illustration of slab-driven mantle deformation zone from high resolution, 3D numerical models of the Alaska subduction-transform system. (a) slab-driven toroidal flow, slab edge related upwelling, and poloidal flow in the mantle surrounding the slab. (b) Viscosity cross section through subset of model domain shows laterally emergent low viscosity region surrounding slab in composite viscosity model. (c) Viscosity profile for Newtonian model (i.e., without the strain-rate dependence in the viscosity flow law). Inset shows profiles of the viscosity for the composite viscosity models (black, gray lines) and Newtonian viscosity models (blue lines). Modified from Jadamec and Billen (2012) and Jadamec (2016). 


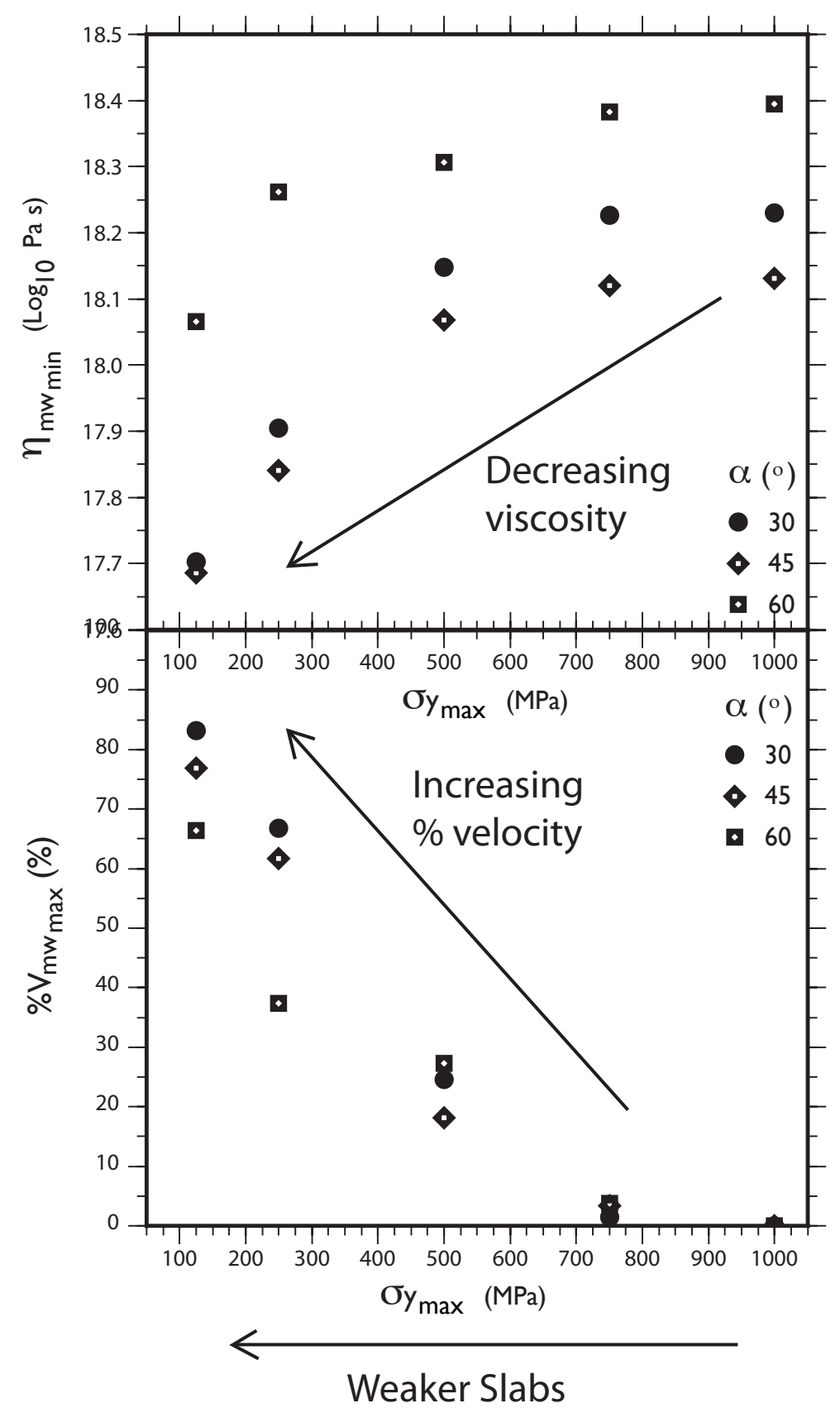

Figure 11: Results from 2D numerical models of subduction using a composite viscosity show decreasing mantle viscosity and increasing mantle flow velocity, as a function on decreasing maximum yield stress (slab strength). (a) Minimum mantle wedge viscosity emergent in the models. (b) Percent change in maximum velocity in mantlegyedge with respect to the models with a highest yield strength. The lower the maximum yield stress, the greater the slab-driven mantle weakening. The faster flow and weaker mantle viscosities are not due to sidewall proximity. Model boundaries are over $1500 \mathrm{~km}$ to the left of the slab and over $2000 \mathrm{~km}$ away to the right and below the slab, making the distance to the model boundaries over 4 and 5 times with length of the slab, respectively. Modified from Jadamec (2016). 
a)
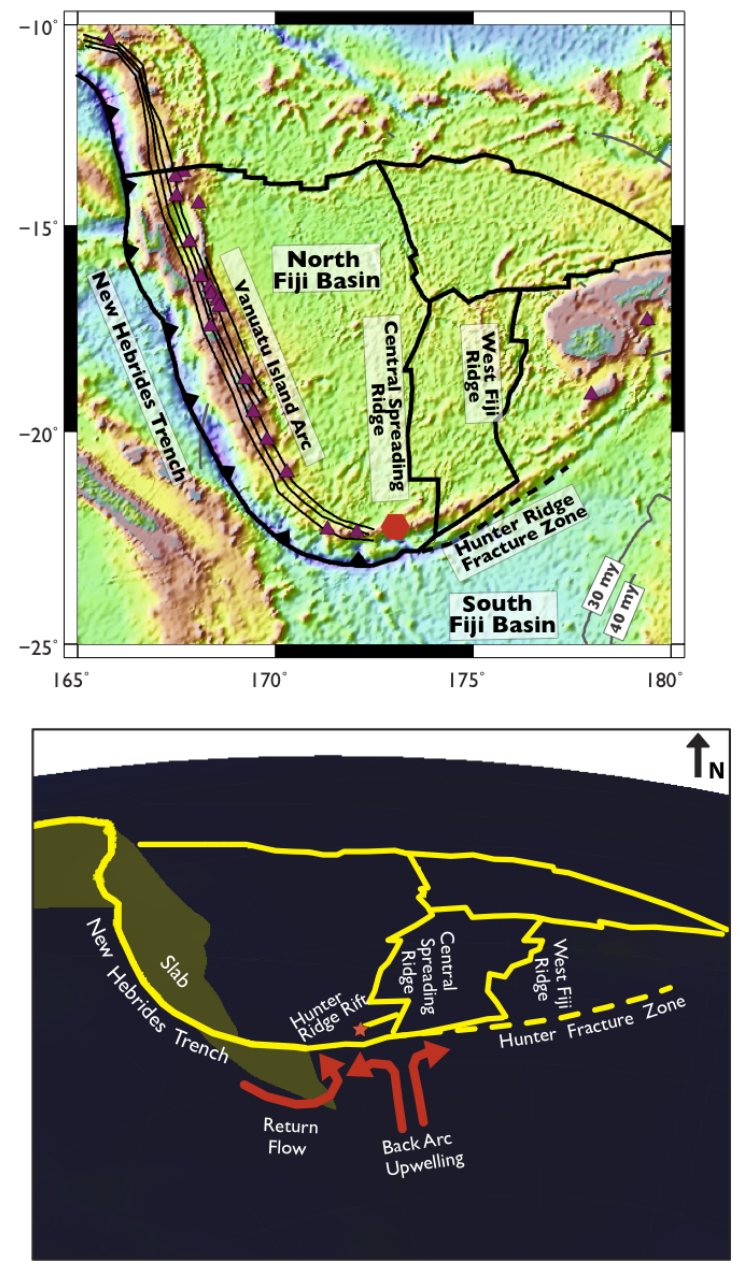

c)

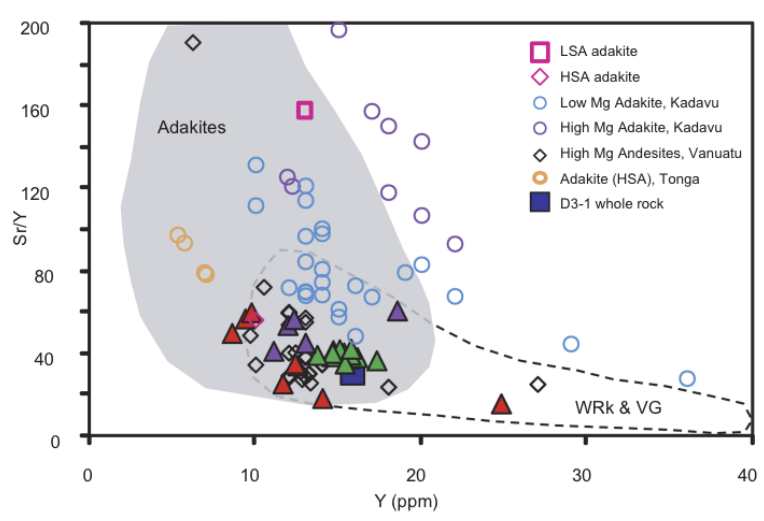

Figure 12: New Hebrides subduction zone intersection with Central Spreading Ridge. (a) Tectonic map. Red star marks slab edge-ridge intersection where D3-1 sample was collected in Durance et al. (2012). Plate boundaries - black lines (Bird, 2003); Slab contours - thin lines, 50 km intervals (Syracuse and Abers, 2006). Holocene and Pleistocene volcanoes - magenta triangles (Smithsonian Institute, Global Volcanism Program). (b) Geodynamic cartoon of slab edge-back arc spreading intersection. (c) Comparison the geochemistry for volcanic samples, suggestive of adakitc geochemistry in sample D3-1. Modified from Durance et al. (2012). 

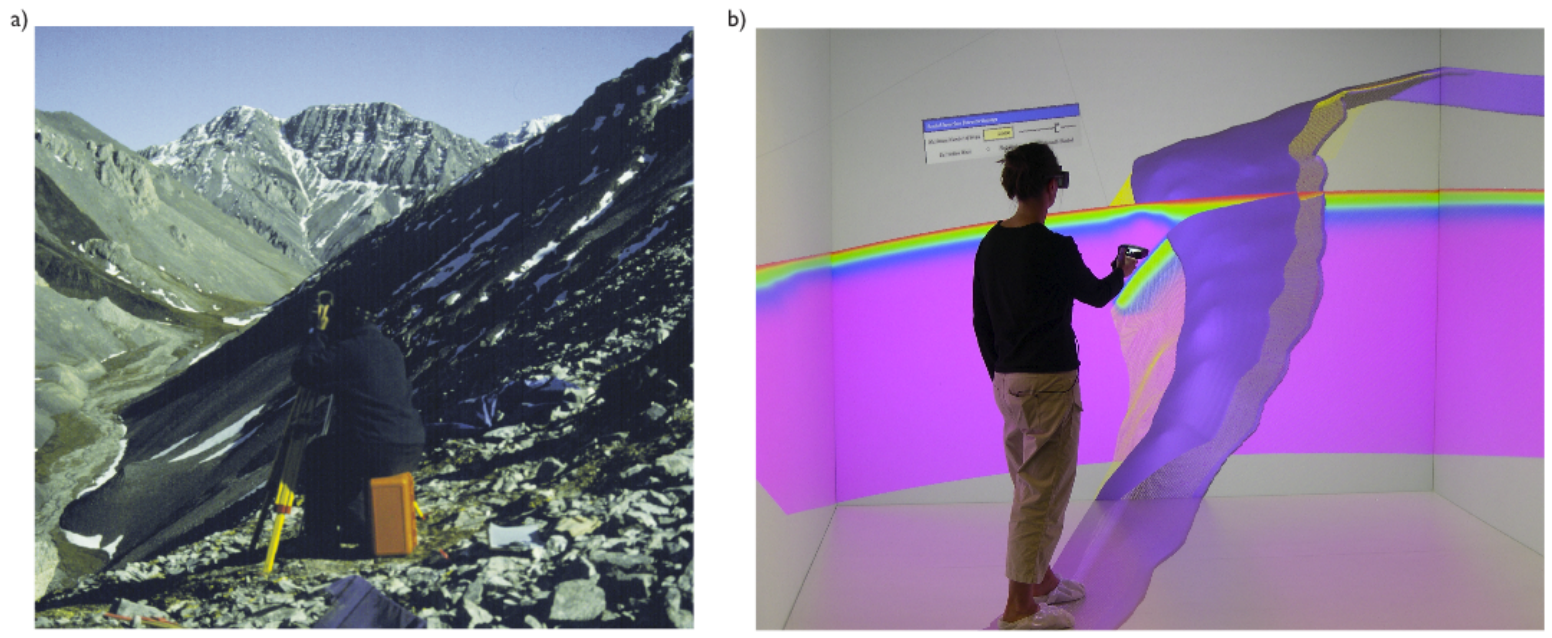

Figure 13: Mapping actual outcrops versus constructing virtual models from digital observations. (a) Recording observations of fold and fault structures forces the field scientist to connect geologic structures in 3D (Jadamec and Wallace, 2014). (b) Mapping complexity at the plate boundary scale onto a high-resolution 3D model grid (up to $\sim 2.5 \mathrm{~km}$ ) forces the geodynamicist to connect platescale structures in 3D. Rainbow - Slice through thermal structure $\left(0-1400^{\circ} \mathrm{C}\right)$; Purple - Isosurface of plate interface volume; Yellow - Wadati-Benioff zone from Jadamec and Billen (2010). Modified from Kellogg et al. (2008). 